\title{
Size distribution and hygroscopic properties of aerosol particles from dry-season biomass burning in Amazonia
}

\author{
J. Rissler ${ }^{1}$, A. Vestin ${ }^{1}$, E. Swietlicki ${ }^{1}$, G. Fisch ${ }^{2}$, J. Zhou ${ }^{1}$, P. Artaxo ${ }^{3}$, and M. O. Andreae ${ }^{4}$ \\ ${ }^{1}$ Div. of Nuclear Physics, Lund University, P.O. Box 118, SE-221 00 Lund, Sweden \\ ${ }^{2}$ Centro Técnico Aeroespacial (CTA/IAE), Praça Marechal Eduardo Gomes, 50, 12228-904, São José dos Campos, Brazil \\ ${ }^{3}$ Institute of Physics, University of Sao Paulo, Rua do Matao, Travessa R, 187, CEP 05508-900, Sao Paulo, Brazil \\ ${ }^{4}$ Max Planck Institute for Chemistry, P.O. Box 3060, 55020 Mainz, Germany
}

Received: 1 July 2005 - Published in Atmos. Chem. Phys. Discuss.: 7 September 2005

Revised: 20 December 2005 - Accepted: 20 December 2005 - Published: 9 February 2006

\begin{abstract}
Aerosol particle number size distributions and hygroscopic properties were measured at a pasture site in the southwestern Amazon region (Rondonia). The measurements were performed 11 September-14 November 2002 as part of LBA-SMOCC (Large scale Biosphere atmosphere experiment in Amazonia - SMOke aerosols, Clouds, rainfall and Climate), and cover the later part of the dry season (with heavy biomass burning), a transition period, and the onset of the wet period.

Particle number size distributions were measured with a DMPS (Differential Mobility Particle Sizer, 3-850 nm) and an APS (Aerodynamic Particle Sizer), extending the distributions up to $3.3 \mu \mathrm{m}$ in diameter. An H-TDMA (Hygroscopic Tandem Differential Mobility Analyzer) measured the hygroscopic diameter growth factors $(G f)$ at $90 \%$ relative humidity $(\mathrm{RH})$, for particles with dry diameters $\left(d_{p}\right)$ between 20-440 nm, and at several occasions RH scans (30$90 \% \mathrm{RH})$ were performed for $165 \mathrm{~nm}$ particles. These data provide the most extensive characterization of Amazonian biomass burning aerosol, with respect to particle number size distributions and hygroscopic properties, presented until now. The evolution of the convective boundary layer over the course of the day causes a distinct diel variation in the aerosol physical properties, which was used to get information about the properties of the aerosol at higher altitudes.

The number size distributions averaged over the three defined time periods showed three modes; a nucleation mode with geometrical median diameters (GMD) of $\sim 12 \mathrm{~nm}$, an Aitken mode (GMD $=61-92 \mathrm{~nm})$ and an accumulation mode (GMD=128-190 nm). The two larger modes were shifted towards larger GMD with increasing influence from biomass burning.
\end{abstract}

Correspondence to: J. Rissler

(jenny.rissler@pixe.lth.se)
The hygroscopic growth at $90 \% \mathrm{RH}$ revealed a somewhat external mixture with two groups of particles; here denoted nearly hydrophobic ( $G f \sim 1.09$ for $100 \mathrm{~nm}$ particles) and moderately hygroscopic $(G f \sim 1.26)$. While the hygroscopic growth factors were surprisingly similar over the periods, the number fraction of particles belonging to each hygroscopic group varied more, with the dry period aerosol being more dominated by nearly hydrophobic particles. As a result the total particle water uptake rose going into the cleaner period. The fraction of moderately hygroscopic particles was consistently larger for particles in the accumulation mode compared to the Aitken mode for all periods. Scanning the H-TDMA over RH (30-90\% RH) showed no deliquescence behavior. A parameterization of both $G f(\mathrm{RH})$ and $G f\left(d_{p}\right)$, is given.

\section{Introduction}

During the recent decade a great deal of effort has been devoted to establish the effects of aerosols on global, as well as regional climate. Aerosol particles affect the global radiation budget directly through back scattering or absorption of solar radiation (Kaufman et al., 1998, 2002). They can also affect the radiation budget and the regional water cycle through inducing changes in the microphysical properties of clouds by acting as cloud droplet condensation nuclei (Kaufman et al., 2002; Lohmann and Feichter, 2005). This is often referred to as the indirect radiative effect of aerosols on climate and is today the largest uncertainty in predicting the future global climate (IPCC, 2001). The direct scattering of solar radiation by aerosol particles may also induce changes in the vertical temperature profile, inducing changes in cloud properties

(C) 2006 Author(s). This work is licensed under a Creative Commons License. 
and precipitation patterns (Koren et al., 2004; Procopio et al., 2004).

The Amazon basin contains a large portion of the world's rainforests, and the area is for many reasons of special importance, for instance as a $\mathrm{CO}_{2}$ sink, supplier of air-cleansing OH-radicals (Crutzen and Andreae, 1990; Davidson and Artaxo, 2004), and of course as living space for numerous species. However, it is also an area where considerable deforestation occurs, with no sign of slowing down (Andreae et al., 2004b). Burning activities in South America constitute almost $30 \%$ of the world's biomass burning activities (Guyon et al., 2005). Vegetation fires in the tropics are one of the world's major sources of new particles, and if injected to the higher troposphere, the particles can be transported over long distances and affect large areas (Andreae et al., 2001). Since the Amazon Basin normally has low background particle concentrations (Rissler et al., 2004; Zhou et al., 2002; Artaxo et al., 2002), the high particle concentrations induced by biomass burning (increasing by as much as $\sim 100$ times during the heavy biomass burning period) together with the intensive hydrological cycle of the area, has a considerable effect on the cloud properties and possibly on the precipitation patterns in Amazonia (Andreae et al., 2004a).

This study was part of LBA-SMOCC (Large Scale Biosphere Atmosphere Experiment in Amazonia - Smoke Aerosols, Clouds, Rainfall and Climate: Aerosols from Biomass Burning Perturb Global and Regional Climate). The LBA-SMOCC overall goal was to investigate the connection between the high concentrations of biomass burning aerosol lowering the effective radius of the cloud droplets forming on this aerosol, and the climatic consequences of the resulting perturbations in cloud microphysics (Andreae et al., 2004a). Even though biomass burning, as a consequence of deforestation, is a large source of new particles, there have only been few studies of the particle emissions in the region. The SMOCC campaign is, until now, the most extensive experiment in Amazonia for the characterization of the physical and chemical properties of the biomass burning aerosol, in combination with large scale airborne cloud microphysics measurements.

In this paper, we focus on the measured number size distributions and hygroscopic properties - two essential properties when considering the direct and indirect effect of aerosols on climate - measured at a ground based site in Rondonia, Brazil, during September-November 2002. This period covers part of the dry period, the transition period, as well as the onset of the wet period in Western Amazonia. The hygroscopic properties are important also when interpreting measurements at ambient RH. No previous studies covering both number size distributions and the hygroscopic growth have yet been made in the area. From the ground base data, together with information about the vertical structure of the atmosphere (from radio sondes and flight vertical profile measurements) the aerosol properties of the residual layer were estimated. This provides information about how particles from biomass burning change as they age in the atmosphere. The particles' density was estimated from comparing the mass predicted from the number size distributions with independently obtained PM2.5 (TEOM measurements). The size distributions as well as the hygroscopic growth data will later be used in a study predicting the CCN (Cloud Condensation Nuclei) concentrations.

This paper is a continuation of two previous studies covering the background aerosol of the tropical rainforest (Rissler et al., 2004; Zhou et al., 2002), as well as an aged biomassburning plume injected to a clean air mass with very few new particle sources (Rissler et al., 2004).

\section{Experiment and data treatment}

\subsection{Description of the measurement campaign}

The LBA-SMOCC ground site was located at the Fazenda Nossa Senhora Aparecida (FNS, $10^{\circ} 45^{\prime} 44^{\prime \prime} \mathrm{S}, 62^{\circ} 21^{\prime} 27^{\prime \prime} \mathrm{W}$, 315 ma.s.l.) in the state of Rondônia in southwestern Amazonia, Brazil. The land at the site is used as a cattle ranch and is a rather flat pasture, surrounded by a series of small hills (ridge heights $300-440 \mathrm{~m}$ ) at distances of $3-4 \mathrm{~km}$. The site was chosen since it can be considered to be representative of the region in southwestern Amazonia with extensive biomass burning during the dry season. More details about the sampling site are found in Andreae et al. (2002), Kirkman et al. (2002) and Trebs et al. (2004).

Measurements of aerosol particle size distributions and hygroscopic properties were conducted at this site from 11 September to 14 November 2002. In this part of the Amazon, the rainy season normally arrives in the middle of October (Ferreira da Costa et al., 1998; Silva Dias et al., 2002) but it was somewhat delayed in 2002 due to a weak El Niño. Thus, the rainy period with low biomass burning activity, and subsequently also low aerosol particle levels, did not arrive until the beginning of November.

The SMOCC campaign was divided into three different meteorological periods;

- The dry period, 11 September-8 October 2002, a period with widespread heavy biomass burning,

- The transition period, 9-30 October 2002, a period during which the intensity of biomass burning was still high but started to decline, and finally

- The wet period, 31 October-14 November 2002, a relatively clean period in the beginning of the wet season. During this period some pyrogenic aerosols and other pollutants are expected both from local sources as well as emissions transported into the region from upwind regions in the southern perimeter of the Amazon Basin, especially from the state of Mato Grosso. 


\subsection{Instrumentation}

\subsubsection{Experimental setup}

The main instruments used for this study were a DMPS and an H-TDMA. Both instruments were sampling from the same inlet located $\sim 5 \mathrm{~m}$ above ground. The inlet removed particles with equivalent aerodynamic diameters $>10 \mu \mathrm{m}$. The DMPS and H-TDMA instruments were identical to those used in two previous studies in the Amazon region (Rissler et al., 2004; Zhou et al., 2002). An APS (Aerodynamic Particle Sizer) was also used, sampling from the same inlet as the DMPS and the H-TMDA, as well as a TEOM (Patashnick and Rupprecht, 1991) sampling from a R\&P PM2.5 inlet. The TEOM was operating at a temperature of 50 degrees centigrade.

In order to study several processes that influences aerosol concentration and dynamics, further measurements referred to in this article are local meteorological and vertical profiles obtained from radio sondes launched several times per day at the site, as well as flight vertical profiles.

\subsubsection{The DMPS}

The DMPS consists of two Vienna type DMAs (Differential Mobility Analyzer; Winklmayr et al., 1991) operating in parallel. A UDMA (ultrafine DMA) measured in the diameter range 3 to $22 \mathrm{~nm}$ and a DMA from 22 to $850 \mathrm{~nm}$, together covering a total of 38 mobility channels in equal steps of logarithmic diameter. Condensation particle counters (TSI CPC 3025 and CPC 7610) are used to detect and count the mobility-classified particles exiting each DMA. The particle counters were calibrated with respect to counting efficiency versus particle diameter prior to the experiment. The number size distributions are measured at dry conditions $(\mathrm{RH}<10 \%)$, and the time required to measure one full number size distribution is 10 minutes.

The various flows were set each day using a separate volume flow meter. The flows were corrected to mass flow by taking into account the pressure drop within the instrument. Interruptions in the DMPS data occurred only in connection with setting of flows, power failures, and filling of butanol in the CPC's. The fraction of time during the SMOCC campaign (11 September to 14 November 2002) for which reliable DMPS data exists is $91 \%$.

The algorithm for inversion of the DMPS data calculates the DMPS kernel matrix and uses the inverse of this to convert the measured mobility distributions to particle number size distributions. Factors taken into account when calculating the matrix are: sampling line losses, bipolar charging probabilities, DMA transfer functions and CPC counting efficiencies (Zhou, 2001).

\subsubsection{The APS}

An aerodynamic particle sizer (TSI APS 3310) was used to measure aerosol number size distributions in the aerodynamic diameter size range 1.2 to $3.3 \mu \mathrm{m}$ (Baron and Willeke, 2001). Since the sheath air supplied to the APS was dehydrated, the dry particle size was measured. The APS was calibrated with respect to particle sizing prior to the experiment. Even though the effective size range of the APS is nominally 0.50 to $20 \mu \mathrm{m}$, a laboratory intercomparsion between the APS used in SMOCC and a newly calibrated APS 3321 showed that the counting efficiency was deficient outside the narrow size range 1.20 to $3.3 \mu \mathrm{m}$. The time resolution used was $10 \mathrm{~min}$ to match that of the DMPS system, and the data was stored by the same data acquisition system.

\subsubsection{The H-TDMA}

The hygroscopic properties were measured with a Hygroscopic Tandem Differential Mobility Analyser (H-TDMA) for dry particle sizes between 20 and $440 \mathrm{~nm}$. The instrument consists mainly of two DMAs, a bipolar charger and humidifiers. In the first DMA, dry aerosol particles in a narrow quasi-monodisperse size interval are selected. The selected particles are humidified and led to a second DMA, where the new, humidified particle size distribution is determined. Two CPCs (TSI CPC 7610) are used to count particles in the aerosol outlet flows of the DMAs. The aerosol and sheath flows entering DMA-2 are humidified separately by passing through Gore-Tex tubes submerged in temperaturecontrolled water baths. For more details, see Svenningsson (1997) and Zhou (2001).

Dry particles were selected and the particle diameter growth factor $G f$ (defined as the ratio between the humidified and dry particle diameter, $d_{\text {wet }} / d_{\text {dry }}$ ) was measured when taken from a dry state $(\mathrm{RH}<15 \%)$ to a controlled state of humidity. During the campaign, the H-TDMA was set to operate in two modes; measuring the $G f$ at $90 \% \mathrm{RH}$ while scanning the selected dry diameter, or measuring the $G f$ of $165 \mathrm{~nm}$ particles (dry diameter) scanning the RH between 30 and $90 \%$. When running $90 \%$ scans, the time resolution scanning the entire size range was $\sim 30-45 \mathrm{~min}$.

Parameters showing the H-TDMA status were logged continuously and used to assure the quality of the data. Requirements for valid scans are shown in Table 1. The parameters logged were; temperatures and RH (measured at 5 different locations in the H-TDMA flow lines), flows, pressures, and particle concentrations. Moreover, the instrument flows were calibrated once every day with a separate volume flow meter, and the performance of the instrument checked daily by measuring the hygroscopic growth of pure ammonium sulfate particles. The correct RH was established as described in Vestin (2005).

The scans deviating in RH from the nominal value (still within the criteria for quality assurance) were corrected to 
Table 1. Criteria used for acceptance of the SMOCC- 2002 H-TDMA data.

\begin{tabular}{|c|c|c|}
\hline Parameter & Criterion & Purpose \\
\hline DMA2 RH average during scan & $86-92 \% *$ & $\begin{array}{l}\text { limit range for comparability } \\
\text { and to allow correction to } 90 \%\end{array}$ \\
\hline DMA2 RH variability during scan & $\pm 1.5 \% \mathrm{RH}$ & $\begin{array}{l}\text { minimize RH fluctuation } \\
\text { during particle classification }\end{array}$ \\
\hline temperature difference sheath - excess flow & $\pm 0.5^{\circ} \mathrm{C}$ & minimize RH gradients in DMA-2 \\
\hline relative standard deviation in $\mathrm{CPC} 1$ concentration & $<0.5$ & particle concentrations stable during scan \\
\hline standard deviation of sheath flow RH & $\begin{array}{l}<1.5 \% \mathrm{RH} \\
+1 \%\end{array}$ & DMA-2 humidity control working properly \\
\hline - " - & $\pm 3 \%$ & aerosol accurate concentr. measurement \\
\hline
\end{tabular}

* Not used when operating in the RH scanning mode.

90\% RH, in order to facilitate a comparison between the various SMOCC H-TDMA observations and with previous experiments. The corrections to nominal $\mathrm{RH}$ were carried out as described in Swietlicki et al. (2000).

A program based on the principles of Stolzenberg and McMurry (1988), was used to fit the peaks of the humidified aerosol distribution with normal distribution functions. Two peaks were needed to adequately describe the observed distributions for the SMOCC data set. This means that the aerosol was somewhat externally mixed. The arithmetic mean diameter growth factor $G f$, diameter growth dispersion factor, and aerosol number fraction were determined for each peak, and these output parameters were used in the further data evaluation.

When presenting H-TDMA data, apart from $G f$, the hygroscopic properties are often described as the soluble particle volume fraction, $\varepsilon$ (Massling et al., 2005; Svenningsson et al., 1994; Swietlicki et al., 1999). This parameter has the advantage over $G f$ that only the hygroscopic properties due to soluble material of the particles (Raoult's law) are considered, and excludes the Kelvin curvature effect. However, when calculating $\varepsilon$ from H-TMDA data without knowing the real molecular weight or particle density, $\varepsilon$ must be calculated using a reference compound, in this study, ammonium sulfate $\left(\varepsilon_{A S}\right)$. The presented $\varepsilon_{A S}$ should not be viewed as the real soluble volume fractions of the aerosol particles, or as if only ammonium sulfate was responsible for the water uptake. The $\varepsilon_{A S}$ should rather be interpreted representing the number of soluble ions or molecules that are present in the particles, determining their hygroscopic growth irrespective of their chemical nature, and expressed as the equivalent amount of ammonium sulfate. The $\varepsilon_{A S}$ is calculated from the measured growth factor as;

$\varepsilon_{A S}=\frac{G f^{3}-1}{G f_{A S}^{3}-1}$.

Here, $G f$ is the measured diameter growth factor, $G f_{A S}$ is the growth factor of a fully soluble particle composed en- tirely of the same solute material (here ammonium sulfate) at the same humidified size as the observed particle. This procedure was designed to take into account the Kelvin curvature correction (Swietlicki et al., 1999; Rissler et al., 2004). $G f_{A S}$ was calculated, taking into account the non-ideal behavior of the model solution, using water activity data from Tang and Munkelwitz (1994). During the SMOCC campaign, the aerosol particles contained large mass fractions of water-soluble organic compounds (WSOC) that in general show less hygroscopic growth than pure ammonium sulfate (Decesari, 2005; Fuzzi et al., 2006 ${ }^{1}$; Mircea et al., 2005; Svenningsson et al., 2005). As a consequence, the actual soluble volume fractions were likely to be larger than the $\varepsilon_{A S}$ calculated here, and it is important to make a distinction between the two concepts. From the point of view of merely providing a description of the hygroscopic behavior and predicting CCN concentrations based on H-TDMA data (Vestin et al., $2006^{2}$ ), the discrepancy between $\varepsilon$ and $\varepsilon_{A S}$ is irrelevant, since the important quantity is the number of soluble ions or molecules that are present in the particle.

As an alternative to $\varepsilon_{A S}$, we here introduce the concept of $\kappa$, representing the number of soluble moles of ions or molecules per unit volume dry particles. This expression has the advantage that the misinterpretations that the soluble material only consists of the model salt, or that the given soluble volume fraction contains all soluble material are avoided. $\kappa$

\footnotetext{
${ }^{1}$ Fuzzi, S., Decesari, S., Facchini, M. C., Cavalli, F., Emblico, L., Mircea, M., Andreae, M. O., Trebs, I., Hoffer, A., Guyon, P., Artaxo, P., Rizzo, L. V., Lara, L. L., Pauliquevis, T., Maenhaut, W., Raes, N., Chi, X., Mayol-Bracero, O. L., Soto, L., Claeys, M., Kourtchev, I., Rissler, J., Swietlicki, E., Tagliavini, E., Schkolnik, G., Falkovich, A.H., Rudich, Y., Fisch, G., and Gatti, L. V.: Overview of the inorganic and organic composition of sizesegregated aerosol in Rondonia, Brazil, from the biomass burning period to the onset of the wet season, J. Geophys. Res., submitted, 2006.

2 Vestin, A., Rissler, J., Swietlicki, E., and Frank, G.: Cloud nucleating properties of aerosol from Amazonian deforestation fires, Atmos. Chem. Phys. Discuss., to be submitted, 2006.
} 
can be calculated either from classical Köhler theory (Köhler, 1936) or from taking the non-ideal behavior into account (i.e., that the real number of soluble ions in a particles differs slightly from the number of soluble ions seen by the electrolyte) through using a model salt. If taking the non-ideal behavior of a model salt into account, using the same salt as when calculating the $\varepsilon_{A S}$, then $\kappa=\varepsilon \cdot v \cdot \rho_{S} / M_{s} . \rho_{S}$ is the density of the model salt, $v$ the number of ions per molecule of the model salt, and $M_{s}$ the salt molecular weight.

We observed an externally mixed aerosol with two groups of particles, having slightly different growth when humidified in the H-TDMA. The two groups were denoted the "nearly hydrophobic group" and the "moderately hygroscopic group" and were present at the same time. The particles were assigned to each of these groups based on their $\varepsilon_{A S}$. The upper limit of the nearly hydrophobic group (equivalent to the lower limit of the moderately hygroscopic group) was for $20-165 \mathrm{~nm}$ particles set to $\varepsilon_{A S}=0.15$, and for 265 and $440 \mathrm{~nm}$ particles to $\varepsilon_{A S}=0.18$. The limit for the $20-165 \mathrm{~nm}$ particles $\left(\varepsilon_{A S}=0.15\right)$ corresponds to $G f$ between 1.11-1.17, and for $265-440 \mathrm{~nm}$ particles $\left(\varepsilon_{A S}=0.18\right)$ to a $G f$ of 1.20 . The span in $G f$ values corresponding to $\varepsilon_{A S}=0.15$ for 20 $165 \mathrm{~nm}$ particles is due to the Kelvin curvature effect. The classification limits of $\varepsilon_{A S}$ were based on the observations and were set to values that optimized the capability to classify the particles. The classification agrees with that used for previous measurements in another part of the Amazon region (Rissler et al., 2004). In a few cases when both hygroscopic groups were present, both groups in the humidified distributions were classified as belonging to the same hygroscopic group (if both groups had $\varepsilon_{A S}<0.15$ ). This was the case in $\sim 4 \%$ of the H-TDMA observations for all but the smallest dry particle diameters $(20 \mathrm{~nm})$, where this classification ambiguity occurred in $15 \%$ of the cases.

\subsection{Boundary layer structure}

As will be described in the following sections, the aerosol particle number concentrations and hygroscopic properties measured at ground level showed strong and consistent diel variations. This behavior is linked to the structure and dynamics of the lowest part of the troposphere (below $\sim 2 \mathrm{~km}$ ), which adjusts to the daily variations in incoming solar radiation. An overview of the general meteorological conditions is given in Fuzzi et al. $\left(2006^{1}\right)$.

During the night, the air is cooled from below as longwave radiation escapes from the ground. This causes a shallow stable layer to form, starting close to ground level in the late afternoon/early evening, reaching a height of $\sim 200 \mathrm{~m}$ around midnight, and slightly higher just before sunrise. Overlying this nocturnal layer (NL), there is a residual layer (RL) - a remnant of the well-mixed convective boundary layer (CBL) from the previous day (Fig. 1). Even though the $\mathrm{RL}$ is still somewhat turbulent during nighttime due to windshear, it eventually becomes decoupled from the air aloft,

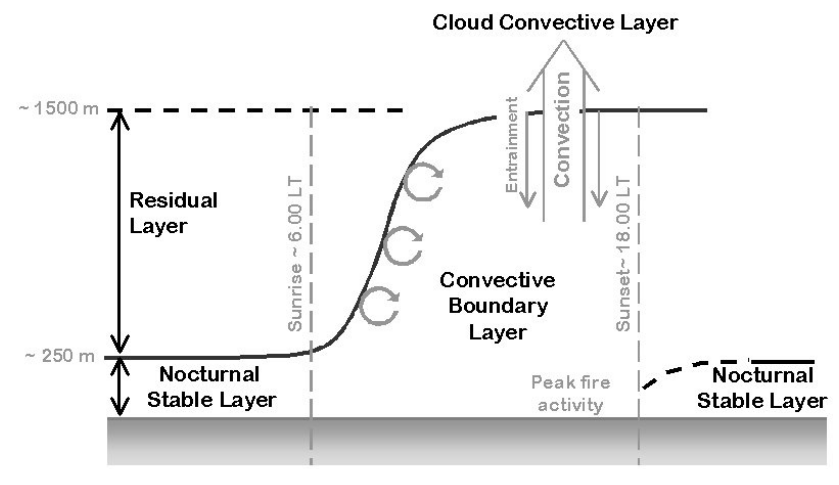

Fig. 1. A schematic figure of the diel evolution of the lower troposphere.

since it normally is capped by a strong temperature inversion. The RL is sometimes referred to as the fossil layer.

As the sun rises ( 06:00 LT) over the pasture, the NL starts dissipating from below due to heating of the ground, and a new and shallow mixed layer starts to develop, here denoted the convective boundary layer (CBL, Fig. 1). The average heights of the CBL during the period 18-30 September 2002 - when the most intense biomass burning activities took place - were: $403 \mathrm{~m}$ (08:00 LT), $1097 \mathrm{~m}$ (11:00 LT), $1609 \mathrm{~m}$ (14:00 LT), and $1685 \mathrm{~m}$ (17:00 LT). The average CBL heights for 15-29 October 2002 - during the transition period with less intense biomass burning - were: $465 \mathrm{~m}$ (08:00 LT), $1036 \mathrm{~m}$ (11:00 LT), $1343 \mathrm{~m}$ (14:00 LT), and $1322 \mathrm{~m}$ (17:00 LT). These CBL heights were estimated from rawinsonde data defining the CBL height as the altitude where the increase in potential temperature first reached a gradient higher than $2 \mathrm{~K} \times \mathrm{km}^{-1}$ (Fisch, 2006 ${ }^{3}$ ). The highest CBL growth rates occur between 08:00 and 11:00 LT, as the NL has been completely eroded and the atmosphere is at neutral atmospheric conditions and free to be mixed by the turbulence. Over the pasture site, the dry season CBL height is higher than during the wet season (by 300-600 m), and also higher than over the rain forest during both the dry and wet seasons (Fisch et al., 2004). This is due to the surface energy partition, since the sensible heat flux is a factor of $\sim 2$ higher over the dry pasture. This is caused by the lower evapotranspiration for the dry pasture, which means that more energy will return to the lower atmosphere as sensible heat instead of latent heat flux.

Around noon, convection becomes strong enough to penetrate the top of the CBL, bringing air from the CBL into the overlying cloud convective layer (CCL). Biomass smoke is therefore dispersed to altitudes above the CBL height, but with concentrations that decrease with altitude within the CCL. Air that is detrained upward from the CBL is ex-

\footnotetext{
${ }^{3}$ Fisch, G.: Boundary layer characteristics at Fazenda Nossa Senhora Aparecida during the RACCI/SMOCC experiment, Atmos. Chem. Phys. Discuss., to be submitted, 2006.
} 


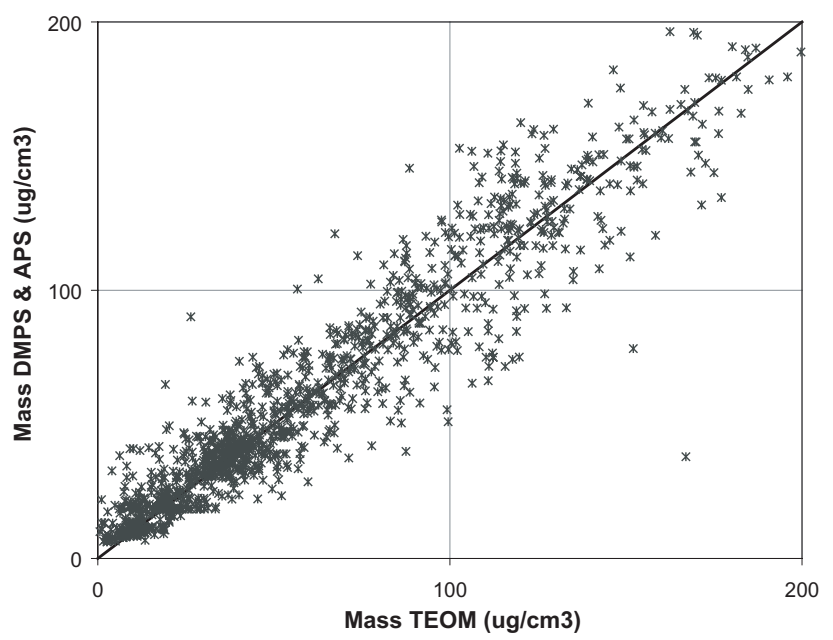

Fig. 2. Correlation plot of the PM2.5 measured by the TEOM and the PM2.5 calculated from DMPS and APS measurements, using a dry density of $1.37 \mathrm{~g}$, for the dry period.

changed by hotter, drier and usually also cleaner air entrained from the CCL aloft (Fig. 1). Shallow convection is normally stopped by the trade wind inversion at altitudes between 3$4 \mathrm{~km}$. In the afternoon, deep convection can penetrate further into the free troposphere. As turbulence due to thermal convection (mainly) and windshear dies out close to sunset, the afternoon air exchange between the CBL and the CCL above decreases and eventually ceases.

As the CBL evolves in height during the morning hours, air from the RL is continuously mixed down into the air from the eroding NL. It can be assumed that the proportion between the volumes of NL and RL air that is being mixed is determined by the height of the NL and the CBL. Knowing the proportion provides an opportunity to use the groundlevel data to estimate the aerosol properties of the RL air, as will be described in Sect. 3.4.

\section{Results and Discussion}

The aerosol particle number size distributions and hygroscopic growth measurements are here presented for the three defined meteorological periods respectively. The diel variation of these aerosol physical properties is used to estimate the corresponding aerosol properties of the residual layer overlying the nocturnal stable layer - using a simple air mass mixing model. A mass closure study comparing the aerosol particle mass derived from the DMPS and APS number size distributions with the mass measured with the TEOM PM2.5 is also presented, together with an estimation of the particle densities.

\subsection{Particle densities}

The combined aerosol particle number size distributions from the DMPS and the APS covered the total size range 3$3300 \mathrm{~nm}$, with a 10-min time resolution. The APS classifies the particles according to their equivalent aerodynamic diameter $d_{a e}$ while the DMPS according to their equivalent mobility diameter $d_{m e}$. The correction for the difference between $d_{a e}$ and $d_{m e}$ was made using the relation $d_{a e}=d_{m e} \cdot \sqrt{ } \rho_{\mathrm{dry}}$, where $\rho_{\text {dry }}$ is the density during the conditions of the measurement, in this case the dry particle density. This relation holds for spherical and non-porous particles (then $d_{m e}$ equals the volume equivalent diameter) as assumed here. To give an estimate of the dry particle mass below $2.5 \mu \mathrm{m}$ (PM2.5), the dry particle number size distribution (3-2500) was converted into volume size distribution, integrated, and multiplied with a dry particle density. The size range between the DMPS and the APS (850- 1200 nm) was linearly interpolated. After taking half-hourly averages, these mass concentrations were compared to the PM2.5 mass measured by the TEOM instrument. Since the TEOM instrument heats the aerosol sample to $50^{\circ} \mathrm{C}$, the aerosol water can be assumed to be evaporated, and the measurement provides the dry particle mass. All three instruments operate at dry conditions and the mass closure study was valid for dehydrated particles.

The DMPS-APS and TEOM mass concentrations were highly correlated (Fig. 2). Using a dry density of $1.38 \mathrm{~g} \times \mathrm{cm}^{-3}$, the correlation coefficient $\left(\mathrm{r}^{2}\right)$ was 0.96 and the slope 1.00 (regression of estimated versus measured PM2.5 mass with zero offset). The dry particle density was fitted to achieve the best agreement between the estimated and measured PM2.5 mass. The same density was used converting equivalent aerodynamic diameter to mobility diameters. Separating the three meteorological periods, a trend with increasing densities was seen. The average densities were estimated to 1.37 for the dry period, and 1.66 for the transition period. The correlation coefficient was 0.96 and 0.84 for the two periods respectively. During the wet period, even higher densities were needed for a closure. No value is presented here due to lower correlation coefficients, probably due to the low mass concentrations (average: $6.5 \mu \mathrm{g} / \mathrm{m}^{3}$ ) making the TEOM PM2.5 data not as reliable as for higher concentrations. Furthermore, the data set was not complete for the wet period. Since the TEOM heats the aerosol sample to $50^{\circ} \mathrm{C}$ while the ambient average temperature for the relevant period is $\sim 30^{\circ} \mathrm{C}$, the true density may be slightly higher due to possible evaporation of semi-volatile compounds.

Previous estimates of biomass burning particle densities are summarized in Reid et al. (2005). The only value found for tropical biomass burning particle density was $1.35 \pm 0.15 \mathrm{~g} \times \mathrm{cm}^{-3}$, given in Reid and Hobbs (1998), which is the average measured by an aircraft in fresh $(<4$ min old $)$ plumes from 12 forest and 6 grass (pasture) fires during the SCAR-B experiment in Amazonia, 1995. 
The size range covered by the APS contributed only $5 \%$ to the PM2.5 mass. The conclusion was that most of the aerosol particle mass in the biomass burning aerosol was confined to the sub-micrometer particle size region. This was also seen by Reid and Hobbs (1998), and Artaxo et al. (1998, 2002).

The primary aerosol particles produced by combustion of biomass in flaming conditions at high temperatures can contain highly agglomerated structures (Rissler et al., 2005) consisting of soot (Posfai et al., 2003; Reid et al., 2005) and alkali salts. The agglomerates found in Rissler et al. (2005) could be described as having a specific fractal dimension $(\sim 2.5)$. Once they are cooled down and humidified in the atmosphere, these structures collapse by condensation of organic compounds and water, and become more compact and near-spherical (Rissler et al., 2005; Weingartner et al., 1997). The apparently near-constant value of the dry particle density is an indication that the observed particles were already collapsed, since variability in the ambient relative humidity would otherwise induce further variability in the mass closure. This was not surprising, since Rissler et al. (2005) found that the particles started to collapse already below $50 \%$ RH.

\subsection{Number Size Distribution}

3.2.1 Comparison of meteorological periods and previous measurements

The average particle number concentrations ( \pm 1 standard deviation) measured with the DMPS for particles with diameters between $30-850 \mathrm{~nm}$ were $10440 \pm 6570,4810 \pm 2720$ and $1280 \pm 820 \mathrm{~cm}^{-3}$ for the dry, transition and wet period respectively. When including particles down to $3 \mathrm{~nm}$ in diameter, the corresponding concentrations were $11440 \pm 6790$, $5550 \pm 3170$ and $2070 \pm 1790 \mathrm{~cm}^{-3}$. Hence, the average number concentration of nucleation mode particles $(<30 \mathrm{~nm}$ diameter) was relatively high and about the same for all periods, around $800-1000 \mathrm{~cm}^{-3}$. For the ground-based DMPS size distributions all spectra showed a bi- or trimodal behavior.

The average number size distributions for each of these three periods were fitted with three lognormal functions; a nucleation mode, an Aitken mode, and an accumulation mode. The average size distributions are shown in Fig. 3a, and the parameterisation of the average size distributions presented in Table 2. The Aitken and the accumulation mode had average geometric mean diameters around 61-92 nm and 128-190 nm respectively, shifted towards the lower size range for the wet (clean) period.

For comparison, Rissler et al. (2004) observed average geometric mean diameters of 68 and $139 \mathrm{~nm}$ for the Aitken and the accumulation modes, respectively, for an air mass that had been affected by heavy biomass burning $2.5-5$ days earlier, but after that had passed over a clean area with very few new particle sources. In the compilation by Reid
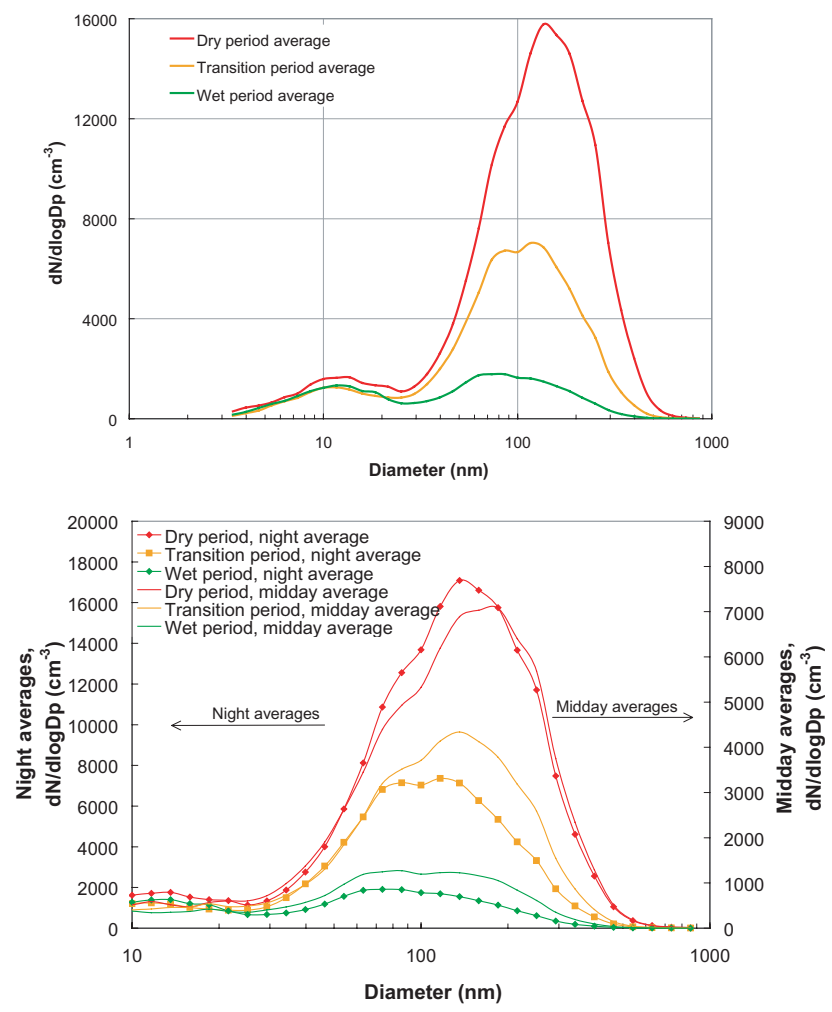

Fig. 3. (a) Average particle number size distributions for the three meteorologically defined periods and (b) average particle number size distributions for the same periods during midday, $\sim 10: 00$ 13:00 LT (right axis) and during nighttime, 20:00-06:00 LT (left axis).

et al. (2005) of the physical properties of biomass burning aerosol particles, the size distributions are described using unimodal lognormal fits. In plumes of fresh smoke from fires burning grass, savanna, cerrado and forest, count median diameters (CMD) between $0.1-0.13 \mu \mathrm{m}$ are reported, and for South American regional biomass burning haze the CMD range between $0.12-0.23 \mu \mathrm{m}$. The single CMD for the SMOCC ground based measurements for the dry period was $\sim 135 \mathrm{~nm}$. During the SMOCC field experiment airborne measurements of particle size distributions (Guyon et al., 2005) showed geometric mean diameters of $110 \pm 15 \mathrm{~nm}$ in 69 plumes within the boundary layer (BL) and $139 \pm 17 \mathrm{~nm}$ for 50 smoke plumes detrained above the BL, mostly from non-precipitating clouds.

The particle number concentrations observed during the relatively clean wet period were still more than a factor of 3 higher than the background concentrations measured at Balbina, a background site $125 \mathrm{~km}$ northeast of Manaus, Brazil (in LBA-CLAIRE-98, Zhou et al. (2002) and in LBACLAIRE-2001, Rissler et al. (2004)). In these two studies, the air masses classified as clean had passed over several hundreds of kilometers of pristine rainforest before reaching the site. The ground site for the SMOCC campaign - FNS 
Table 2. Statistics of the particle number size distribution. The average number size distribution (DMPS) for the period; dry (11 Sep-8 Oct 2005), transition (9 Oct-30 Oct, 2005) as well as the wet period (31 Oct-14 Nov) were fitted with three log normal distributions. Both the total average was fitted, the mid day averages ( 10:00-13:00 LT) as well as afternoon/night averages (15:00-20:00 LT). $n$ denotes number of spectra available.

\begin{tabular}{|c|c|c|c|c|c|c|c|c|c|}
\hline Mode and period & $\begin{array}{c}\text { Number conc. } \\
\left(\mathrm{cm}^{-3}\right)\end{array}$ & $\begin{array}{c}\text { Geom. Mean diam. } \\
(\mathrm{nm})\end{array}$ & Geom. Stdev. & $\begin{array}{l}\text { Number conc. } \\
\left(\mathrm{cm}^{-3}\right)\end{array}$ & $\begin{array}{c}\text { Geom. Mean diam. } \\
(\mathrm{nm})\end{array}$ & Geom. Stdev. & $\begin{array}{c}\text { Number conc. } \\
\left(\mathrm{cm}^{-3}\right)\end{array}$ & $\begin{array}{l}\text { Geom. Mean diam. } \\
(\mathrm{nm})\end{array}$ & Geom. Stdev \\
\hline & & Diurnal average & & & Day average & & & fternoon/night average & \\
\hline Dry period & $n=3560$ & & & $n=407$ & & & $n=596$ & & \\
\hline Accumulation & 5214 & 190 & 1.53 & 2119 & 205 & 1.48 & 4810 & 165 & 1.57 \\
\hline Aitken & 5213 & 92 & 1.63 & 2691 & 98 & 1.74 & 4803 & 84 & 1.61 \\
\hline Nucleation & 1090 & 12 & 1.82 & 453 & 11 & 2.00 & 1800 & 11 & 1.81 \\
\hline Trans. period & $n=2857$ & & & $n=351$ & & & $n=555$ & & \\
\hline Accumulation & 3708 & 131 & 1.69 & 1789 & 166 & 1.55 & 2938 & 149 & 1.58 \\
\hline Aitken & 984 & 66 & 1.39 & 1087 & 76 & 1.50 & 1803 & 73 & 1.52 \\
\hline Nucleation & 841 & 12 & 1.89 & 392 & 16 & 2.13 & 1534 & 10 & 1.7 \\
\hline Wet period & $n=2085$ & & & $n=233$ & & & $n=327$ & & \\
\hline Accumulation & 785 & 128 & 1.66 & 427 & 165 & 1.48 & 488 & 145 & 1.52 \\
\hline Aitken & 406 & 61 & 1.39 & 490 & 68 & 1.51 & 393 & 62 & 1.46 \\
\hline Nucleation & 849 & 12 & 1.82 & 325 & 12 & 2.00 & 1455 & 10 & 1.78 \\
\hline
\end{tabular}

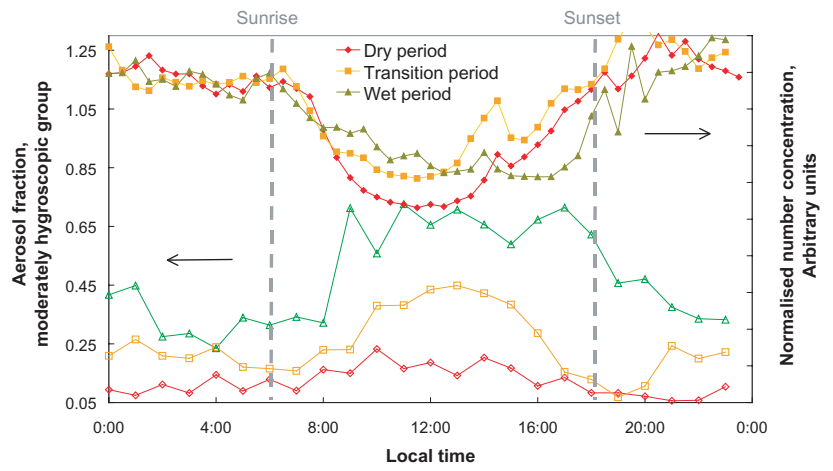

Fig. 4. The average 24-hour variation in particle concentrations for particles $>30 \mathrm{~nm}$ (right axis) and the fraction of hygroscopic particles (left axis), averaged for each of the three SMOCC periods.

- was located in an area of the Rondônia state that, except from heavy biomass burning, is influenced by human activities such as traffic, cooking and charcoal production. Furthermore, only the beginning of the wet period was studied during SMOCC, and some fires were still present regionally. Some pyrogenic aerosols and other pollutants must also be expected to have been transported into the region from upwind regions in the southern perimeter of the Amazon Basin.

\subsubsection{Diel variation}

A strong diel pattern was seen in the particle number concentrations (Fig. 4). This was a result of the changing structure of the lowest troposphere and the timing of the fire activities over the course of the day. In Fig. 4, the averaged 24-h variation in particle concentrations for particles $>30 \mathrm{~nm}$ is shown for each of the three SMOCC periods. The increase in particle concentrations from the lowest daytime concentrations to the nighttime concentrations was a factor of 2.5, 1.9 and 1.8 for the dry, transition and wet periods respectively.

During nighttime, the average concentrations and number size distributions were fairly stable. Through the night a tendency with slightly decreasing particle concentrations was observed (Fig. 4) and for the most polluted period a slow and small increase in diameter was discerned. Since the PM0.85 (calculated from the DMPS measurements) showed no decrease in concentration, a plausible explanation for the decrease in number particle concentrations could be coagulation. Other possible mechanisms processing the aerosol are condensation and dry deposition. However, the particle physical properties are relatively constant during the night and the evolution small. Generally, no strong particle sources seem to be present, however, during some nights plumes from individual fires were observed.

A shift during daytime towards slightly larger sizes was seen in the average number size distributions. This is illustrated in Fig. 3b. Note that the nighttime and daytime distributions are plotted using different y-axes. The midday number size distributions were averaged for the time period when the concentrations stabilized at the lowest concentrations ( 10:00-13:00 LT). The average daytime CMD (for particles $>30 \mathrm{~nm}$ ) was $6 \%, 16 \%$ and $14 \%$ higher than the average nighttime values for the dry, transition and wet periods respectively. As will be described in section 3.4, the CMD of the estimated nighttime aerosol distributions of the residual layer were shifted by as much as $11 \%, 24 \%$ and $32 \%$ compared to the nighttime aerosol distributions of the nocturnal stable layer.

In addition to the lognormal fitting parameters of the average number size distributions, Table 2 also describes the midday average distributions $(\sim 10: 00-13: 00 \mathrm{LT})$ as well as the afternoon/evening distributions (15:00-20:00 LT). The 
midday distributions are representative for the time of day when particle number concentrations reach their lowest values. The reason for the minimum is twofold. Firstly, during daytime the CBL develops so that the cleaner air in the RL layer has mixed with the more polluted air from the previous NL, thus reducing the number concentrations. Secondly, the peak fire activity occurs in the middle to late afternoon (Prins et al., 1998) increasing the particle concentrations. The afternoon/evening distributions are representative for the aerosol during the peak fire activity.

A few days during the most heavily polluted period did not display the same diel pattern as most other days. During these days $(21,22$ and partly 25 September) the daytime concentrations stayed high with particle concentrations $\sim 20000 \mathrm{~cm}^{-3}$ (>30 nm). This could be a sign of the convection being depressed due to the high particle concentration or cloudiness (Fuzzi et al., 2006 ${ }^{1}$ ).

\subsubsection{Nucleation mode particles}

During all three periods the grand average distributions had a geometric mean diameter for the nucleation mode at $12 \mathrm{~nm}$, with modal average number concentrations around 800 $1000 \mathrm{~cm}^{-3}$ (Table 2 and Fig. 3a). Although the number concentration of the nucleation mode particles displayed a clear diel variation (Fig. 5), it differed significantly from that of the larger particles (Fig. 4). The nucleation mode particles appeared strongly at about 05:00-07:00 LT, around sunrise. As the CBL developed, the particle counts were reduced and particles were only sporadically present during daytime. Normally the nucleation particles rapidly started to increase again around sunset, at about the time when the NL started to form. During the evenings and nighttime, nucleation mode particles were present in relatively high concentrations until around midnight.

This diel pattern is very similar to that seen previously in the wet-to-dry transition period at the clean background site near Balbina, (CLAIRE 2001, Rissler et al., 2004), despite the fact that these two sets of observations were made in distinctly different air masses and levels of pollution. This behavior of the nucleation mode - which appears to be characteristic for various seasons and locations in the Amazon region - is also decisively different from that observed at most other continental sites (Kulmala et al., 2004). Observations of nucleation mode particles were made also during the campaign CLAIRE-98 (Zhou et al., 2002) at the Balbina site during the wet period 1998, using the same DMPS system and data inversion procedure. However, these observations differed from what was observed here and during CLAIRE 2001. In Zhou et al. (2002) the nucleation mode particles were larger, fewer and did not show the same diel pattern.

During SMOCC, the nucleation mode was present - if using the same criterion as in CLAIRE 2001 (Rissler et al., 2004), requiring particle concentrations $>60 \mathrm{~cm}^{-3}$ for particles with a diameter $<30 \mathrm{~nm}-$ in $93 \%, 72 \%$ and $78 \%$

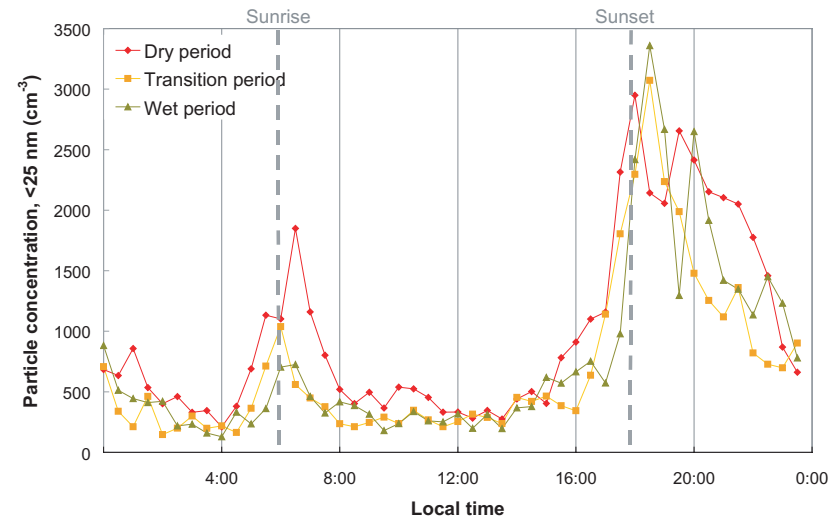

Fig. 5. Diel variation in the nucleation mode particle concentration, averaged for each of the three SMOCC periods.

of the cases for the dry, transition and wet period respectively. The corresponding frequencies of occurrence during CLAIRE 2001 (Rissler et al., 2004) were around 70$80 \%$ and during CLAIRE-98 44\%. However, the nucleation mode concentrations were considerably higher during SMOCC $\left(\sim 800 \mathrm{~cm}^{-3}\right)$ compared to during CLAIRE 2001 at the rain forest site in Balbina $\left(\sim 300 \mathrm{~cm}^{-3}\right)$.

As observed previously in the Amazon region, particles in the very low size range $(\sim 3-5 \mathrm{~nm})$ were only sporadically present, and not as abundant as would be expected if nucleation took place at the site. However, the particles were not very much larger, with the main concentration in the size range $10-15 \mathrm{~nm}$.

In Zhou et al. (2002), a hypothesis was laid out that the nucleation mode particles formed at higher altitudes and were transported down to ground level by vertical mixing. This is not consistent with what was observed in the morning hours, since the nucleation mode appeared in the early morning hours when the depth of convection is still very low, both in this study and in CLAIRE 2001. Neither could this mechanism explain the presence of the nucleation mode during the evening hours. The mode was also occasionally present at daytime during rain events and when large cumulus passed the site, what could be consistent with the hypothesis of Zhou et al. (2002) about particles being transported down by downdrafts. The mechanism behind these various nucleation phenomena might be different.

The possibility that the mode was due to traffic on the road $\sim 800$ m north east of the site could not be ruled out, but is not likely since the consistent diel pattern was found also during CLAIRE 2001 at Balbina, a site not close to any large roads. Also the number size distributions did not look like those expected from traffic. The nucleation mode particles found were smaller in size than generally observed from traffic. Furthermore, traffic does not solely produce nucleation particles but also larger particles, which were not observed (Kristensson et al., 2004). Neither did the chemical analysis 
show any large contribution from traffic (Fuzzi et al., 2006 ${ }^{1}$ ).

In Trebs et al. (2004) a diel pattern with a peak in total ammonium concentration around 08:00-09:00 LT was reported. This peak is not correlated with the peak in the nucleation mode particles and does most likely not have any connection to the observed nucleation events. Many questions remain about the mechanism behind the nucleation mode particles and the issue needs to be further investigated.

\subsection{Hygroscopic behavior}

The hygroscopic diameter growth was measured more or less continuously during the whole campaign, with short interruptions for calibration scans and setting of flows. The aerosol particles were in most cases found to be externally mixed with respect to their hygroscopic properties, and hence also with regard to chemical composition (Table 3). As described in Sect. 2.2.4, the particles were classified into two groups, denoted nearly hydrophobic and moderately hygroscopic. From the hygroscopic diameter growth factors $(G f)$ of each group, soluble volume fractions $\left(\varepsilon_{A S}\right)$ as well as number of moles soluble molecules or ions per unit volume dry particles $(\kappa)$ were calculated using ammonium sulfate as reference compound (see Sect. 2.2.4).

The particle dry size selected by the H-TMDA closest to the CMD of the average size distributions was $d_{p}=110 \mathrm{~nm}$. At $90 \% \mathrm{RH}$, the average $G f$ for these particles were 1.09 and 1.26 for each hygroscopic group, respectively. This corresponds to $\varepsilon_{A S} \approx 0.08$ and $\varepsilon_{A S} \approx 0.27$. The $G f$ increased slightly as a function of particle dry size, with the exception of the very smallest particles $(<35 \mathrm{~nm})$ of the moderately hygroscopic group (see Table 3 ). In general, the number fraction of the nearly hydrophobic group was larger for the Aitken mode particles $(<100 \mathrm{~nm}$ in diameter) than for the larger accumulation mode particles (Fig. 6). The hygroscopic properties for each meteorological period are summarized in Table 3.

\subsubsection{Comparison between the meteorological time periods}

The hygroscopic growth factors of both groups were surprisingly similar for each of the three periods, with a weak increase in growth of the moderately hygroscopic group when going from the heavily polluted period into the cleaner period. When comparing the three periods, the main difference in hygroscopic behavior was seen not in the growth factors, but in the number fraction of the two groups (Fig. 6). During the dry period, the aerosol was clearly dominated by particles belonging to the nearly hydrophobic group. As the wet season approached the aerosol number fraction for the moderately hygroscopic group increased. As a result the average number of soluble ions/molecules per particle (here including both hygroscopic groups) rises going into the cleaner period and consequently the total particle water uptake in- creases. During the wet period, the moderately hygroscopic particles dominated for aerosol particles $>135 \mathrm{~nm}$.

\subsubsection{Diel variation}

The averaged 24-hour variations in the hygroscopic growth factor and the aerosol fraction displayed a diel pattern. In the morning hours, as the eroding NL started to mix with air from the RL, the fraction of moderately hygroscopic particles increased significantly. The increase was most pronounced during the transition and the wet period. The diel pattern in the aerosol number fraction of the hygroscopic groups correlates rather well with the diel pattern in number concentration (Fig. 4). The variations in hygroscopic growth factors over the course of the day were small, as was the variation growth factors comparing the three SMOCC periods. The diel fluctuations could only be observed in the growth of particles belonging to the nearly hydrophobic group, and showed a maximum relative increase during daytime of $(d G f / G f) \sim 5 \%$. Such small fluctuations were seen for all meteorological periods. In Table $3 \mathrm{~b}$ the hygroscopic behavior observed during midday ( 10:00-13:00 LT) is presented, representative of the aerosol properties during cloud formation.

\subsubsection{RH scans}

Occasionally during the SMOCC campaign, the H-TDMA was set to scan over RH instead of particle dry size. The RH was then varied from $\sim 30 \%$ up to $\sim 90 \%$, for $165 \mathrm{~nm}$ particles. The RH scans were performed in order to study whether the hygroscopic properties observed at $\mathrm{RH}=90 \%$ can be used to deduce information also for intermediate $\mathrm{RH}$ values. The water uptake as a function of RH is important for the radiative transfer in the troposphere (aerosol direct radiative effect), aqueous phase chemistry, and phase partitioning of highly water-soluble gases such as $\mathrm{HNO}_{3}$. Also, the water uptake can be used in various corrections needed to evaluate data from aerosol samplers operating at humidified conditions.

The available RH scans were classified into five groups as being either dry period afternoon/night scans (performed 22, 25 and 26 September $2002 \sim 15: 00-19: 00$ LT), dry period midday scans (performed 24 and 26 September 2002 $\sim 09: 00-14: 00 \mathrm{LT}$ ), transition period afternoon/night scans (performed 16 October $2002 \sim 15: 00-18: 00$ LT), transition period midday scans (performed 11 Sept and 16 October $2002 \sim 10: 00-14: 00$ LT) and wet period afternoon/night scans (14 November $2002 \sim 21: 00-24: 00$ LT). No RH scans were performed during midday for the wet period.

The RH scans did not display any obvious step-like deliquescent behavior (Fig. 7). Instead, all scans could be fitted with a continuous one-parameter function,

$G f=\left[1+A \cdot\left(\frac{R H / 100}{1-R H / 100}\right)\right]^{\frac{1}{3}}$ 
Table 3. Summary of the H-TDMA observations of hygroscopic growth at $90 \% \mathrm{RH}$ for the defined periods; dry, transition and wet. Both the total averages (a) as well as the midday averages (b), 10:00-13:00 LT, are given. In the table, the number fraction presented corresponds to the average number fraction when the group is present. The total number fraction is given by; frequency of occurrence multiplied with the given number fraction. $G f$ denotes measured diameter growth factor, $e_{A S}$ the fictive soluble volume fraction referring to $\left(\mathrm{NH}_{4}\right)_{2} \mathrm{SO}_{4}$ and $k$ denotes the corresponding moles of soluble ions or molecules/dry particle volume.

\begin{tabular}{|c|c|c|c|c|c|c|c|c|}
\hline \multirow{2}{*}{$\begin{array}{l}\text { Diurnal average } \\
\text { Growth factor at } 90 \% \mathrm{RH}\end{array}$} & \multicolumn{8}{|c|}{ Dry particle diameter } \\
\hline & $20 \mathrm{~nm}$ & $35 \mathrm{~nm}$ & $50 \mathrm{~nm}$ & $75 \mathrm{~nm}$ & $110 \mathrm{~nm}$ & $165 \mathrm{~nm}$ & $265 \mathrm{~nm}$ & $440 \mathrm{~nm}$ \\
\hline \multicolumn{9}{|l|}{ Dry period } \\
\hline \multicolumn{9}{|l|}{ Nearly hydrophobic particles } \\
\hline Frequency of occurrence & $77 \%$ & $99 \%$ & $100 \%$ & $100 \%$ & $100 \%$ & $99 \%$ & $99 \%$ & $93 \%$ \\
\hline \multirow[t]{2}{*}{$G f \pm 1$ s.d. } & 1.065 & 1.060 & 1.065 & 1.070 & 1.082 & 1.100 & 1.117 & 1.102 \\
\hline & \pm 0.030 & \pm 0.024 & \pm 0.022 & \pm 0.025 & \pm 0.027 & \pm 0.029 & \pm 0.035 & \pm 0.044 \\
\hline Number fraction & 0.91 & 0.94 & 0.95 & 0.91 & 0.88 & 0.84 & 0.69 & 0.47 \\
\hline (when present) & \pm 0.21 & \pm 0.11 & \pm 0.08 & \pm 0.11 & \pm 0.15 & \pm 0.21 & \pm 0.29 & \pm 0.24 \\
\hline$\varepsilon_{A S}$ & 0.071 & 0.064 & 0.063 & 0.064 & 0.071 & 0.084 & 0.097 & 0.082 \\
\hline$\kappa\left(/ \mathrm{m}^{3}\right)$ & 2868 & 2584 & 2549 & 2554 & 2850 & 3388 & 3900 & 3283 \\
\hline$A$ & 0.019 & 0.021 & 0.023 & 0.025 & 0.030 & 0.037 & 0.044 & 0.037 \\
\hline \multicolumn{9}{|l|}{ Moderately hygrosc. particles } \\
\hline Frequency of occurrence & $54 \%$ & $30 \%$ & $35 \%$ & $49 \%$ & $49 \%$ & $51 \%$ & $66 \%$ & $92 \%$ \\
\hline \multirow[t]{2}{*}{$G f \pm 1$ s.d. } & 1.247 & 1.200 & 1.226 & 1.222 & 1.236 & 1.260 & 1.263 & 1.287 \\
\hline & \pm 0.086 & \pm 0.071 & \pm 0.058 & \pm 0.053 & \pm 0.044 & \pm 0.043 & \pm 0.043 & \pm 0.038 \\
\hline Number fraction & 0.56 & 0.23 & 0.15 & 0.18 & 0.24 & 0.32 & 0.48 & 0.62 \\
\hline (when present) & \pm 0.38 & \pm 0.19 & \pm 0.076 & \pm 0.086 & \pm 0.14 & \pm 0.22 & \pm 0.22 & \pm 0.21 \\
\hline$\varepsilon_{A S}$ & 0.365 & 0.240 & 0.252 & 0.229 & 0.233 & 0.252 & 0.247 & 0.269 \\
\hline$\kappa\left(/ \mathrm{m}^{3}\right)$ & 14652 & 9663 & 10111 & 9199 & 9358 & 10118 & 9946 & 10828 \\
\hline A & 0.104 & 0.081 & 0.094 & 0.092 & 0.099 & 0.111 & 0.113 & 0.126 \\
\hline$A$, both modes & 0.045 & 0.025 & 0.027 & 0.031 & 0.038 & 0.049 & 0.066 & 0.087 \\
\hline \multicolumn{9}{|l|}{ Transition period } \\
\hline \multicolumn{9}{|l|}{ Nearly hydrophobic particles } \\
\hline Frequency of occurrence & $72 \%$ & $95 \%$ & $97 \%$ & $98 \%$ & $98 \%$ & $96 \%$ & $97 \%$ & $95 \%$ \\
\hline \multirow{2}{*}{$G f \pm 1$ s.d. } & 1.065 & 1.072 & 1.073 & 1.079 & 1.089 & 1.099 & 1.115 & 1.096 \\
\hline & \pm 0.029 & \pm 0.024 & \pm 0.026 & \pm 0.030 & \pm 0.034 & \pm 0.034 & \pm 0.037 & \pm 0.040 \\
\hline Number fraction & 0.83 & 0.93 & 0.91 & 0.87 & 0.77 & 0.62 & 0.42 & 0.41 \\
\hline (when present) & \pm 0.22 & \pm 0.12 & \pm 0.12 & \pm 0.14 & \pm 0.22 & \pm 0.26 & \pm 0.19 & \pm 0.13 \\
\hline$\varepsilon_{A S}$ & 0.0849 & 0.0779 & 0.0724 & 0.0722 & 0.0779 & 0.0838 & 0.0951 & 0.0767 \\
\hline$\kappa\left(/ \mathrm{m}^{3}\right)$ & 3413 & 3133 & 2910 & 2903 & 3129 & 3367 & 3823 & 3082 \\
\hline \multirow{2}{*}{\multicolumn{9}{|c|}{ Moderately hygrosc. particles }} \\
\hline & & & & & & & & \\
\hline Frequency of occurrence & $74 \%$ & $40 \%$ & $51 \%$ & $64 \%$ & $72 \%$ & $86 \%$ & $96 \%$ & $100 \%$ \\
\hline \multirow[t]{2}{*}{$G f \pm 1$ s.d. } & 1.260 & 1.231 & 1.223 & 1.243 & 1.255 & 1.264 & 1.283 & 1.317 \\
\hline & \pm 0.087 & \pm 0.068 & \pm 0.050 & \pm 0.053 & \pm 0.044 & \pm 0.034 & \pm 0.039 & \pm 0.034 \\
\hline Number fraction & 0.55 & 0.30 & 0.23 & 0.24 & 0.34 & 0.47 & 0.62 & 0.62 \\
\hline (when present) & \pm 0.36 & \pm 0.29 & \pm 0.21 & \pm 0.19 & \pm 0.22 & \pm 0.24 & \pm 0.16 & \pm 0.15 \\
\hline$\varepsilon_{A S}$ & 0.387 & 0.283 & 0.247 & 0.255 & 0.255 & 0.255 & 0.270 & 0.306 \\
\hline$\kappa\left(/ \mathrm{m}^{3}\right)$ & 15573 & 11365 & 9929 & 10242 & 10267 & 10264 & 10867 & 12296 \\
\hline A & 0.111 & 0.096 & 0.092 & 0.102 & 0.109 & 0.113 & 0.123 & 0.143 \\
\hline$A$, both modes & 0.059 & 0.034 & 0.034 & 0.039 & 0.051 & 0.067 & 0.090 & 0.101 \\
\hline \multicolumn{9}{|l|}{ Wet period } \\
\hline Number of observations & 159 & 197 & 205 & 205 & 205 & 206 & 204 & 166 \\
\hline Nearly hydrophobic particles & & & & & & & & \\
\hline Frequency of occurrence & $67 \%$ & $85 \%$ & $86 \%$ & $95 \%$ & $96 \%$ & $89 \%$ & $92 \%$ & $87 \%$ \\
\hline$G f \pm 1$ s.d. & 1.055 & 1.081 & 1.090 & 1.092 & 1.092 & 1.107 & 1.125 & 1.085 \\
\hline & \pm 0.031 & \pm 0.026 & \pm 0.026 & \pm 0.032 & \pm 0.033 & \pm 0.036 & \pm 0.039 & \pm 0.056 \\
\hline Number fraction & 0.670 & 0.917 & 0.906 & 0.769 & 0.541 & 0.397 & 0.343 & 0.405 \\
\hline (when present) & \pm 0.27 & \pm 0.17 & \pm 0.19 & \pm 0.26 & \pm 0.26 & \pm 0.21 & \pm 0.17 & \pm 0.2 \\
\hline$\varepsilon_{A S}$ & 0.071 & 0.088 & 0.090 & 0.086 & 0.080 & 0.091 & 0.104 & 0.069 \\
\hline$\kappa\left(/ \mathrm{m}^{3}\right)$ & 2838 & 3552 & 3614 & 3438 & 3222 & 3660 & 4199 & 2764 \\
\hline & 0.019 & 0.029 & 0.033 & 0.034 & 0.033 & 0.040 & 0.047 & 0.031 \\
\hline Moderately hygrosc. particles & & & & & & & & \\
\hline Frequency of occurrence & $82 \%$ & $40 \%$ & $40 \%$ & $60 \%$ & $90 \%$ & $99 \%$ & $100 \%$ & $99 \%$ \\
\hline$G f \pm 1$ s.d. & 1.216 & 1.210 & 1.211 & 1.243 & 1.269 & 1.285 & 1.323 & 1.352 \\
\hline & \pm 0.060 & \pm 0.066 & \pm 0.051 & \pm 0.039 & \pm 0.034 & \pm 0.036 & \pm 0.049 & \pm 0.053 \\
\hline Number fraction & 0.67 & 0.56 & 0.54 & 0.45 & 0.53 & 0.66 & 0.69 & 0.65 \\
\hline (when present) & \pm 0.32 & \pm 0.38 & \pm 0.38 & \pm 0.27 & \pm 0.24 & \pm 0.23 & \pm 0.19 & \pm 0.22 \\
\hline & 0.310 & 0.253 & 0.232 & 0.254 & 0.272 & 0.280 & 0.320 & 0.352 \\
\hline$\kappa\left(/ \mathrm{m}^{3}\right)$ & 12472 & 10182 & 9327 & 10200 & 10936 & 11271 & 12850 & 14134 \\
\hline A & 0.089 & 0.086 & 0.086 & 0.103 & 0.116 & 0.124 & 0.146 & 0.164 \\
\hline$A$, both modes & 0.057 & 0.042 & 0.044 & 0.052 & 0.073 & 0.094 & 0.115 & 0.117 \\
\hline
\end{tabular}


Table 3. Continued.

\begin{tabular}{|c|c|c|c|c|c|c|c|c|}
\hline \multirow{2}{*}{$\begin{array}{l}\text { Midday average (10:00-13:00 } \\
\text { LT), Growth factor at } 90 \% \mathrm{RH}\end{array}$} & \multicolumn{8}{|c|}{ Dry particle diameter } \\
\hline & $20 \mathrm{~nm}$ & $35 \mathrm{~nm}$ & $50 \mathrm{~nm}$ & $75 \mathrm{~nm}$ & $110 \mathrm{~nm}$ & $165 \mathrm{~nm}$ & $265 \mathrm{~nm}$ & $440 \mathrm{~nm}$ \\
\hline \multicolumn{9}{|l|}{ Dry period } \\
\hline $\begin{array}{l}\text { Number of observations } \\
\text { Nearly hydrophobic particles }\end{array}$ & 46 & 58 & 55 & 66 & 57 & 59 & 58 & 37 \\
\hline Frequency of occurrence & $70 \%$ & $95 \%$ & $100 \%$ & $100 \%$ & $100 \%$ & $97 \%$ & $98 \%$ & $84 \%$ \\
\hline \multirow[t]{2}{*}{$G f \pm 1$ s.d. } & 1.073 & 1.078 & 1.085 & 1.090 & 1.100 & 1.124 & 1.135 & 1.110 \\
\hline & \pm 0.030 & \pm 0.019 & \pm 0.020 & \pm 0.022 & \pm 0.027 & \pm 0.024 & \pm 0.029 & \pm 0.038 \\
\hline Number fraction & 0.86 & 0.94 & 0.95 & 0.91 & 0.81 & 0.81 & 0.64 & 0.40 \\
\hline (when present) & \pm 0.29 & \pm 0.14 & \pm 0.10 & \pm 0.11 & \pm 0.20 & \pm 0.24 & \pm 0.31 & \pm 0.27 \\
\hline$\varepsilon_{A S}$ & 0.095 & 0.084 & 0.084 & 0.083 & 0.088 & 0.106 & 0.114 & 0.088 \\
\hline$\kappa\left(/ \mathrm{m}^{3}\right)$ & 3830 & 3384 & 3376 & 3334 & 3526 & 4266 & 4564 & 3554 \\
\hline A & 0.026 & 0.028 & 0.031 & 0.033 & 0.037 & 0.047 & 0.051 & 0.041 \\
\hline \multicolumn{9}{|l|}{ Moderately hygrosc. particles } \\
\hline Frequency of occurrence & $50 \%$ & $26 \%$ & $35 \%$ & $56 \%$ & $67 \%$ & $63 \%$ & $76 \%$ & $92 \%$ \\
\hline \multirow[t]{2}{*}{$G f \pm 1$ s.d. } & 1.208 & 1.209 & 1.270 & 1.248 & 1.247 & 1.278 & 1.284 & 1.277 \\
\hline & \pm 0.062 & \pm 0.062 & \pm 0.070 & \pm 0.056 & \pm 0.060 & \pm 0.055 & \pm 0.063 & \pm 0.041 \\
\hline Number fraction & 0.80 & $0.4 \pm$ & 0.15 & 0.17 & 0.29 & 0.34 & 0.49 & 0.72 \\
\hline (when present) & \pm 0.31 & 0.334 & \pm 0.11 & \pm 0.10 & \pm 0.18 & \pm 0.29 & \pm 0.27 & \pm 0.22 \\
\hline$\varepsilon_{A S}$ & 0.297 & 0.252 & 0.312 & 0.261 & 0.247 & 0.274 & 0.274 & 0.259 \\
\hline$\kappa\left(/ \mathrm{m}^{3}\right)$ & 11944 & 10109 & 12536 & 10479 & 9942 & 10993 & 11009 & 10402 \\
\hline$A$ & 0.085 & 0.085 & 0.117 & 0.105 & 0.104 & 0.121 & 0.124 & 0.120 \\
\hline$A$, both modes & 0.049 & 0.034 & 0.035 & 0.039 & 0.050 & 0.062 & 0.079 & 0.094 \\
\hline \multicolumn{9}{|l|}{ Transition period } \\
\hline \multicolumn{8}{|l|}{ Nearly hydrophobic particles } & 22 \\
\hline Frequency of occurrence & $37 \%$ & $86 \%$ & $95 \%$ & $100 \%$ & $90 \%$ & $85 \%$ & $95 \%$ & $86 \%$ \\
\hline \multirow[t]{2}{*}{$G f \pm 1$ s.d. } & 1.081 & 1.102 & 1.105 & 1.109 & 1.116 & 1.127 & 1.141 & 1.099 \\
\hline & \pm 0.031 & \pm 0.018 & \pm 0.021 & \pm 0.022 & \pm 0.030 & \pm 0.027 & \pm 0.035 & \pm 0.036 \\
\hline Number fraction & 0.59 & 0.88 & 0.89 & 0.82 & 0.66 & 0.46 & 0.32 & 0.34 \\
\hline (when present) & \pm 0.30 & \pm 0.16 & \pm 0.11 & \pm 0.15 & \pm 0.21 & \pm 0.21 & \pm 0.16 & \pm 0.11 \\
\hline$\varepsilon_{A S}$ & 0.107 & 0.113 & 0.106 & 0.102 & 0.104 & 0.109 & 0.119 & 0.079 \\
\hline$\kappa\left(/ \mathrm{m}^{3}\right)$ & 4284 & 4533 & 4255 & 4096 & 4163 & 4386 & 4787 & 3182 \\
\hline$A$ & 0.029 & 0.038 & 0.039 & 0.040 & 0.043 & 0.048 & 0.054 & 0.037 \\
\hline \multicolumn{9}{|l|}{ Moderately hygrosc. particles } \\
\hline Frequency of occurrence & $94 \%$ & $57 \%$ & $62 \%$ & $88 \%$ & $98 \%$ & $98 \%$ & $100 \%$ & $100 \%$ \\
\hline \multirow{2}{*}{$G f \pm 1$ s.d. } & 1.213 & 1.247 & 1.239 & 1.286 & 1.269 & 1.268 & 1.292 & 1.320 \\
\hline & \pm 0.064 & \pm 0.083 & \pm 0.065 & \pm 0.057 & \pm 0.053 & \pm 0.037 & \pm 0.039 & \pm 0.032 \\
\hline Number fraction & 0.83 & 0.42 & 0.24 & 0.20 & 0.41 & 0.6 & 0.70 & 0.71 \\
\hline (when present) & \pm 0.28 & \pm 0.37 & \pm 0.27 & \pm 0.15 & \pm 0.27 & \pm 0.24 & \pm 0.17 & \pm 0.16 \\
\hline$\varepsilon_{A S}$ & 0.306 & 0.307 & 0.270 & 0.309 & 0.274 & 0.261 & 0.282 & 0.309 \\
\hline$\kappa\left(/ \mathrm{m}^{3}\right)$ & 12307 & 12355 & 10844 & 12438 & 11001 & 10481 & 11319 & 12423 \\
\hline A & 0.087 & 0.105 & 0.100 & 0.125 & 0.116 & 0.116 & 0.129 & 0.144 \\
\hline$A$, both modes & 0.075 & 0.054 & 0.048 & 0.055 & 0.073 & 0.089 & 0.106 & 0.112 \\
\hline \multicolumn{9}{|l|}{ Wet period } \\
\hline \multicolumn{8}{|l|}{ Nearly hydrophobic particles } & 27 \\
\hline Frequency of occurrence & $24 \%$ & $52 \%$ & $86 \%$ & $83 \%$ & $85 \%$ & $81 \%$ & $91 \%$ & $78 \%$ \\
\hline \multirow[t]{2}{*}{$G f \pm 1$ s.d. } & 1.054 & 1.096 & 1.128 & 1.124 & 1.115 & 1.120 & 1.146 & 1.112 \\
\hline & \pm 0.028 & \pm 0.030 & \pm 0.016 & \pm 0.018 & \pm 0.031 & \pm 0.034 & \pm 0.036 & \pm 0.066 \\
\hline Number fraction & 0.40 & 0.88 & & 0.74 & 0.36 & 0.18 & 0.2 & 0.37 \\
\hline (when present) & \pm 0.34 & \pm 0.26 & $1.00 \pm 0$ & \pm 0.29 & \pm 0.25 & \pm 0.64 & \pm 0.14 & \pm 0.24 \\
\hline$\varepsilon_{A S}$ & 0.070 & 0.105 & 0.131 & 0.117 & 0.102 & 0.103 & 0.124 & 0.092 \\
\hline$\kappa\left(/ \mathrm{m}^{3}\right)$ & 2818 & 4230 & 5274 & 4717 & 4103 & 4151 & 4986 & 3711 \\
\hline A & 0.019 & 0.035 & 0.048 & 0.047 & 0.043 & 0.045 & 0.056 & 0.042 \\
\hline Moderately hygrosc. particles & & & & & & & & \\
\hline Frequency of occurrence & $95 \%$ & $64 \%$ & $14 \%$ & $58 \%$ & $93 \%$ & $100 \%$ & $100 \%$ & $96 \%$ \\
\hline$G f \pm 1$ s.d. & 1.180 & 1.173 & 1.180 & 1.225 & 1.256 & 1.269 & 1.318 & 1.350 \\
\hline & \pm 0.029 & \pm 0.038 & \pm 0.0047 & \pm 0.034 & \pm 0.037 & \pm 0.036 & \pm 0.055 & \pm 0.062 \\
\hline Number fraction & 0.95 & 0.85 & & 0.66 & 0.75 & 0.86 & 0.77 & 0.74 \\
\hline (when present) & \pm 0.11 & \pm 0.31 & $1.00 \pm 0$ & \pm 0.26 & \pm 0.18 & \pm 0.092 & \pm 0.15 & \pm 0.22 \\
\hline$\varepsilon_{A S}$ & 0.251 & 0.201 & 0.192 & 0.231 & 0.256 & 0.262 & 0.315 & 0.349 \\
\hline$\kappa\left(/ \mathrm{m}^{3}\right)$ & 10075 & 8081 & 7722 & 9280 & 10294 & 10514 & 12658 & 14021 \\
\hline$A$ & 0.072 & 0.068 & 0.072 & 0.093 & 0.109 & 0.116 & 0.144 & 0.162 \\
\hline$A$, both modes & 0.066 & 0.053 & 0.051 & 0.064 & 0.088 & 0.105 & 0.124 & 0.128 \\
\hline
\end{tabular}



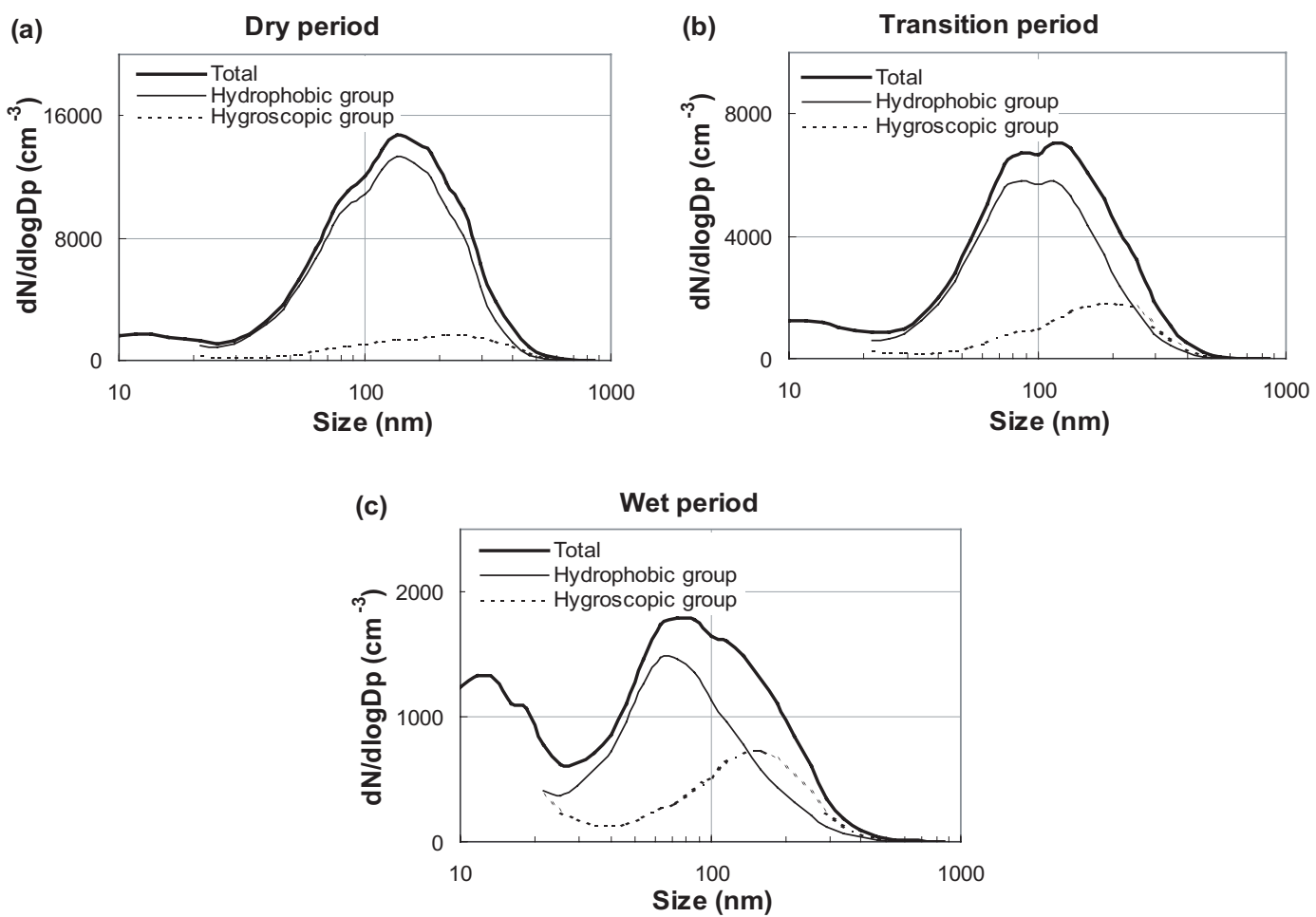

Fig. 6. Average particle number size distributions (bold line) for the three meteorological periods separated into the nearly hydrophobic (thin line) and moderately hygroscopic group (dashed line).

where $A$ was the only fitted parameter needed to account for the observed growth as a function of RH (in \%). The formula is based on classical Köhler theory and is derived and described in Kreidenweis et al. (2005), in a form originally using three fitted parameters. In Köhler theory, more strictly, water activity $\left(a_{w}\right)$ should replace RH in Eq. (2). Equation (2) and the values of $A$ presented in (Tables 3 and 4) describe the water uptake at subsaturations and we do not recommend extrapolation $>95 \% \mathrm{RH}$.

The parameterized $G f$ as well as the measured values are shown, for two of the periods, in Fig. 7. Since the nearly hydrophobic and moderately hygroscopic groups could not be separated at $\mathrm{RH}<80 \%$, both hygroscopic groups were added to provide one average growth factor for each H-TMDA scan. Plotted in Fig. 7 are also the average $G f$ s of the $90 \%$ scans, taken for the same meteorological period. The difference seen in hygroscopic growth (as well as in $A$ when comparing $A$ for the $165 \mathrm{~nm} \mathrm{90 \%} \mathrm{scans} \mathrm{in} \mathrm{Tables} 3$ and 4) is due to the short time periods during which the RH scans were performed. The fitted $A$ values for the RH scans are presented in Table 4. The values of $A$ presented in Table 3 are more representative for the longer meteorological time periods, and we recommend that these values should be used to estimate typical hygroscopic growth factors for each of the meteorological periods.

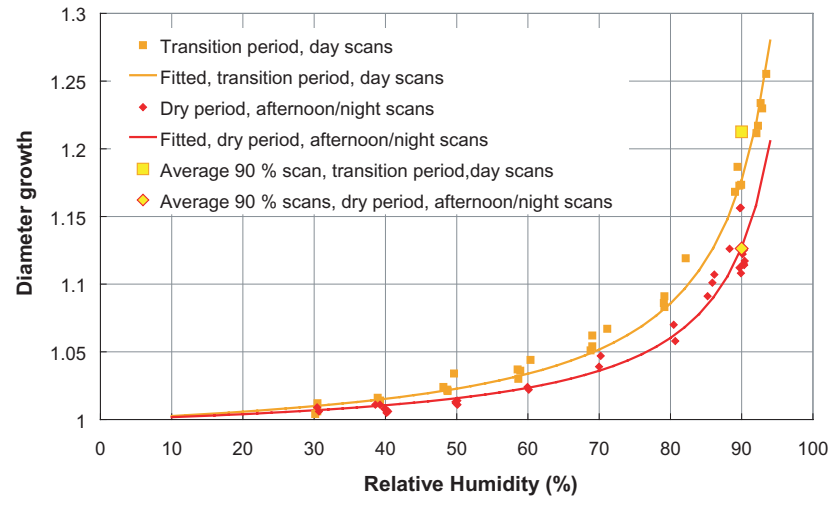

Fig. 7. The $G f$ as a function of RH - parameterized and measured values - for two selected periods. The $G f$ represent the average growth of both groups. The yellow marks are the average growths of the $90 \%$ scans, taken for the same period.

The single-parameter fit used here implicitly assumes that the number of moles of soluble ions or molecules per dry particle volume does not change with RH in the interval 30 $90 \%$ for any of the five RH scan groups. The quality of the fits did not improve significantly when applying three fitted parameters, as in Kreidenweis et al. (2005) and Dick et al. (2000). Additional free parameters could otherwise be used to partly account for the behavior of non-ideal solutions 
Table 4. Parameterizations of the RH scans (165 nm), see Eq. (2).

\begin{tabular}{cccccc}
\hline & Dry period day scans & $\begin{array}{c}\text { Dry period afternoon/ } \\
\text { night scans }\end{array}$ & Trans. period day scans & $\begin{array}{c}\text { Trans. period afternoon/ } \\
\text { night scans }\end{array}$ & $\begin{array}{c}\text { Wet period afternoon/ } \\
\text { night scan }\end{array}$ \\
\hline$A$ & 0.065 & 0.048 & 0.070 & 0.061 & 0.077 \\
\hline
\end{tabular}

Table 5. Parameterizations of A as a function of size, see Eq. (3).

\begin{tabular}{lccc}
\hline & $B$ & $C$ & $D$ \\
\hline Dry period average & 0.0124 & 0.000127 & -0.000214 \\
Trans. period average & 0.0668 & 0.0000261 & -0.0845 \\
Wet per. average & 0.0894 & -0.0000264 & -0.103 \\
Dry per. midday & 0.0459 & 0.0000474 & -0.0476 \\
Trans. per. midday & 0.0983 & -0.0000598 & -0.120 \\
Wet per. midday & 0.140 & -0.00013 & -0.184 \\
\hline
\end{tabular}

(variable van't Hoff factors or osmotic coefficients) and limited solubility. The available data preclude any definite conclusions to be drawn regarding any possible non-ideal solution behavior or minor effects of compounds with limited solubility that goes into solution as $\mathrm{RH}$ increases. Nevertheless, Eq. (2) describes the $G f$ as a function of RH at down to $30 \% \mathrm{RH}$, within the errors introduced due to temporal variability.

Since the RH scans could be reproduced by a stable number of ions in the interval 30-90\% RH, this implies that the H-TDMA-estimate of the number of soluble ions or molecules present in the particles, derived from the observations at $\mathrm{RH}=90 \%$, may also be applicable at higher $\mathrm{RH}$. This is investigated further in Vestin et al. $\left(2006^{2}\right)$ where the SMOCC H-TDMA is used to predict the critical supersaturation and the $\mathrm{CCN}$ (cloud condensation nucleus) concentrations. When extrapolating the hygroscopic growth measured at $90 \% \mathrm{RH}$ to supersaturated conditions, poorly soluble compounds such as $\mathrm{K}_{2} \mathrm{SO}_{4}$ or WSOC, if gradually going into solution, may cause an underestimation of the hygroscopic growth and consequently lead to an overestimation of the critical supersaturation needed for droplet activation.

If replacing RH by $a_{w}$ (Raoult's law) and assuming that the droplet solution behaves ideal, the parameter $A$ could be related to the parameter $\kappa$ introduced in Sect. 2.2.4 as $A=\kappa \cdot M_{w} / \rho_{w}$, where $M_{w}$ and $\rho_{w}$ are the molecular weight and density of pure water. However, when calculating the $\kappa$ presented in Table 3, we took into account the non-ideal behavior of the solution (as described in 2.2.4), resulting in a slightly larger $\kappa$ than if assuming an ideal droplet solution.

\subsubsection{Parameterisation of H-TDMA data}

In Table 3 we present a dimensionless parameter $A$, which together with Eq. (2) describes the hygroscopic diameter growth as a function of RH. As mentioned previously, we recommend using the value of $A$ presented in Table 3 to estimate $G f$ at various $\mathrm{RH}$ (for $<95 \% \mathrm{RH}$ ). To further facilitate the use of H-TDMA data, Acan be parameterized as a function of particle dry size, $d_{p}$, using the equation

$A\left(d_{p}\right)=\log \left(d_{p}\right) \cdot B+d_{p} \cdot C+D$

where $B, C$ and $D$ are fitted parameters. The parameters are presented in Table 5. The parameterisation is valid for the size interval $35-440 \mathrm{~nm}$. For the midday periods, the parameterisation slightly deviates from the measured value for the $35 \mathrm{~nm}$ particles. For sizes larger than 440 we recommend to use the $A$ value for the $440 \mathrm{~nm}$ particles. Note that Eq. (2) and (3) combines the hygroscopic growth of both the nearly hydrophobic and the moderately hygroscopic particle groups as a number-weighted average for each dry particle size. The data in Table 3 can be used to derive similar parameterizations also for each hygroscopic group separately, if needed.

3.3.5 Comparison to results from previous campaigns in Amazonia

The hygroscopic growth factors of the two defined groups were surprisingly similar to those observed during previous campaigns at the clean Amazonian background site, Balbina, during the wet season (CLAIRE-98; Zhou et al., 2002) and the wet-to-dry transition period (CLAIRE-2001; Rissler et al., 2004). This was despite the fact that the air masses differed considerably in pollution level. However, as for the various SMOCC periods, a significant difference was seen in the number fraction attributed to each hygroscopic group. For the previous measurements in the pristine rain forest, the moderately hygroscopic group dominated, as opposed to the nearly hydrophobic group for the polluted SMOCC periods.

\subsection{Residual layer and vertical mixing}

There are several issues motivating the calculations presented in this section regarding the properties of the RL aerosol. To begin with, the RL aerosol is more processed and aged compared to the aerosol at ground level during the afternoon hours (within the peak fire activities) and the evening and 
early night (with smoldering fires). An estimate of the residual layer (RL) aerosol properties can therefore provide information regarding the locally produced fresh biomass burning aerosol in relation to that of the regional haze. Furthermore, it will give insight into the net effect of the aging processes that work on the biomass burning aerosol on the time scale of several hours to 1-3 days. It also serves as a test of consistency between the meteorological data (radio sondes) and the ground-level observations regarding the structure of the lower troposphere (CBL, NL and the RL). Finally, it might provide information about the (upward) ventilation rate of the late afternoon CBL and the RL.

The diel pattern of the Aitken and accumulation mode particles - with respect to particle number concentrations, size distributions, and hygroscopic properties - can be explained by the changing structure of the boundary layer over the course of the day (see Sect. 2.3 for a more detailed description of the development of the convective boundary layer (CBL), the nocturnal layer (NL) and the residual layer (RL)). As the NL is being eroded during the morning hours, the air from the NL will be mixed with the air of the old RL. Since the main fire activities and the more intense convection (causing also entrainment of cleaner air from the free troposphere) do not appear until the middle of the afternoon, the time period between sunrise and noon can be used to obtain additional information about the properties of the RL aerosol on the basis of the ground-based measurements only.

Rawinsonde data provide the height of the CBL at 08:00, 11:00, 14:00, and 17:00, local time (LT) for the dry and transition periods (given in Sect. 2.3). The calculations to derive the properties of the RL aerosol were made for 11:00 LT. At this time of day, we assume that the air is well mixed within the CBL, and that no fire activities disturb the (averaged) ground-based observations. Furthermore, we also assume that the entrainment rate is still weak and can be neglected until this time (11:00 LT; Fig. 1).

The relation between the heights of the CBL at 11:00 LT and the NL determines the relative amounts of air contributed from the RL and the NL. The height of the CBL at 11:00 LT, hCBL(11), was $1097 \mathrm{~m}$ and $1036 \mathrm{~m}$ for the dry and transition period, respectively, and the height of the NL, hNL, was estimated as $220 \mathrm{~m}$ from a simple model using radiative cooling (Fisch, 2006 ${ }^{3}$ ). The heights of the CBL and NL used here agreed with those observed from aircraft during SMOCC (Guyon et al., 2005). The aerosol properties of the $\mathrm{RL}, C_{R L}$, (number concentration, size distribution, hygroscopic properties) can then be estimated from:

$C_{R L}=\frac{C_{C B L}(t) h_{C B L}(t)-C_{N L} h_{N L}}{h_{C B L}(t)-h_{N L}}$.

Here, $C_{N L}$ and $C_{C B L}(11)$ are the corresponding aerosol properties of the NL and the CBL at 11:00LT. The $C_{N L}$ was taken from the averaged DMPS and H-TDMA data for 02:00-06:00 LT (sunrise at 06:00 LT). The aerosol properties at 11:00LT, $C_{C B L}(11)$, were taken to be the parti- cle concentrations and size distributions averaged from the DMPS measurements between 10:50-11:00 LT, while the hygroscopic properties were averaged for 10:00-12:00 LT. The longer time interval was chosen for the H-TDMA data to get more reliable data.

As a test of the consistency of the assumptions made, the measured particle concentrations of the CBL and NL, together with the estimated particle concentrations in the RL (based on CBL height measurements at 11:00 LT) were used to estimate the development of the CBL height at 08:00 LT. This was made using Eq. (4) factoring out $h_{C B L}(t)$. The estimated CBL height at 08:00 LT agrees within $\sim 100 \mathrm{~m}$ with those provided by the rawinsonde data. In the same way, the afternoon CBL heights could be estimated. However, since fire activities start in early afternoon for the dry and transition period, particle concentrations start to increase and Eq. (4) breaks down.

For the wet period, the particle concentrations decreased until $\sim 17: 00$ LT (Fig. 4). This indicates that no strong sources were present during the afternoons and that our simple model could be used to estimate the CBL height also at 14:00 and 17:00 LT (sunset 18:00 LT). Unfortunately, no rawinsonde data was available for the SMOCC wet period. However, Fisch et al. (2004) provide typical values for the CBL heights in the fully established wet season (January-February 1999) measured at the same site as for the SMOCC experiment. These CBL heights are considerably lower (94 $\mathrm{m}$ at 08:00 LT, $475 \mathrm{~m}$ at 11:00 LT, $775 \mathrm{~m}$ at 14:00 LT, and $927 \mathrm{~m}$ at 17:00 LT) than during the SMOCC dry season campaign. Since the "wet" period used in this work only captures the beginning of the actual wet period, we estimate the CBL heights during this period by taking the average of the CBL heights for the SMOCC transition period and the 1999 wet season. Using our simple model to predict the CBL height at 08:00 LT, 14:00 LT and 17:00 LT for the period resulted in CBL heights close to the values from the averaged rawinsonde data, typically within $100 \mathrm{~m}$. If instead, using data from the wet season (Fisch et al., 2004) or that for the SMOCC transition period, it was not possible to predict reasonable $\mathrm{CBL}$ heights. This gives credibility to the estimation of the CBL heights for the SMOCC wet period (31 October-14 November 2002) as an average of those for the SMOCC transition period and the 1999 wet season.

The estimated number size distributions of the RL layer as well as the NL are presented in Fig. 8, for the dry and wet periods, respectively. The count median diameters of the RL average number size distributions are increased by $11 \%, 24 \%$ and $32 \%$ for the dry, transition and wet periods respectively, compared with the NL night averages (here 02:00-06:00 LT). The size distributions of the RL were further divided into the nearly hydrophobic and moderately hygroscopic group. The group that differed most in concentrations between RL and NL was the dominating nearly hydrophobic group, indicating that the sources at ground were producing nearly hydrophobic particles, while the more processed particles in the 

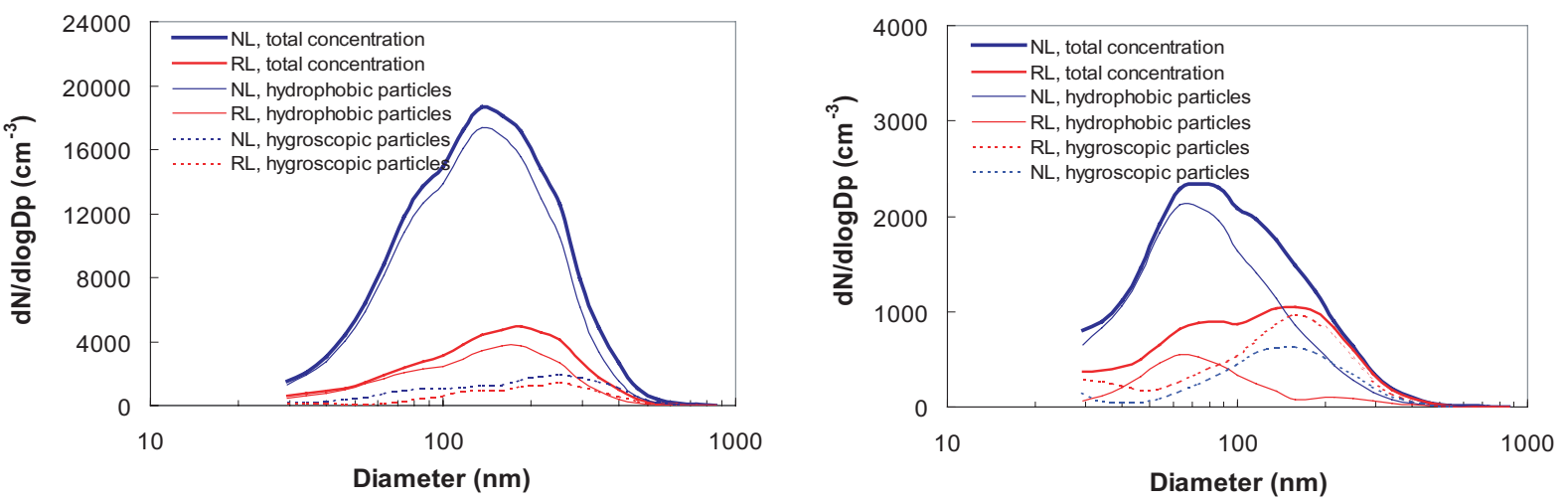

Fig. 8. Number size distributions of the NL, 00:00-06:00 LT (blue curve) and the predicted number size distributions of the RL (red curve), separated into the nearly hydrophobic (thin line) and moderately hygroscopic group (dashed line). Left panel shows the dry period and the right the wet periodod.

RL were more hygroscopic. The derived particles properties should only be taken qualitatively and the uncertainties are large.

\subsection{Discussion}

Downward-mixing of cleaner air from aloft is the most plausible explanation for the decreasing particle number concentrations at ground level during the morning hours. The concurrent shift in the size distribution towards larger sizes might partly be caused by photochemical production of condensable compounds that partition to the aerosol particles, but this fails to explain the observed concentration reduction. Furthermore, the rapid change in the number fraction of the hygroscopic groups during the morning hours, and the fact that the CBL heights at 08:00 LT could be adequately reproduced using our simple model, are clear indications that the RL aerosol properties differ significantly from those of the $\mathrm{NL}$ and that the size shift most plausible is because larger particles from the RL were being mixed down. Similar diel variations were also observed in both fine and coarse particle concentrations of PM and various aerosol inorganic and organic compounds (Fuzzi et al., 2006 ${ }^{1}$ ).

The diel pattern was seen for all three meteorological periods, indicating that significant sources of new particles at ground level were still present even during the period defined as the SMOCC wet (clean) period. At the beginning of November fires were still reported in Rondônia and in the nearby Mato Grosso state (Fuzzi et al., 2006 ${ }^{1}$ ). During two previous campaigns carried out in the pristine Amazonian rainforest, no similar diel pattern was found (Rissler et al., 2004; Zhou et al., 2002). Instead, during a period under the influence of an aged biomass-burning plume (injected 2-5 days earlier into an area with very few new particle sources at ground level) during CLAIRE 2001, an inverted diel pattern was found, due to higher concentrations aloft as a result of long-range transport of biomass burning aerosol.
Six vertical profiles of the lower troposphere were measured using an instrumented aircraft over the SMOCC ground site. All six profiles were performed during the SMOCC dry period, and four of these during the afternoons. The total particle number concentrations were measured with a TSI 3022 condensation particle counter (Chand et al., 2005; Guyon et al., 2005). The aircraft only spent a few minutes at low altitudes $(<700 \mathrm{~m}$ above ground level) when ascending or descending over FNS (315 m a.s.l.). These aircraft observations showed no consistent decrease in particle concentrations (as expected if a strong source at ground and slow vertical mixing) within the CBL, with concentrations that were very similar to those measured at the ground, integrated from the DMPS size distributions. Particle concentrations in the cloud convective layer (CCL) overlying the CBL were always lower, and in many cases much lower, than those in the $\mathrm{CBL}$ and at ground-level. The conclusion from these observations is that the SMOCC daytime CBL was turbulent and well mixed, and that the biomass burning smoke was efficiently dispersed throughout the CBL vertical column. This agrees with the neutral stratification of the CBL seen by the radio sondes.

During the hours from sunrise until noon there were generally relatively weak sources of new particles, and Eq. (4) could be used to estimate the aerosol properties of the RL. In the afternoon hours, during the peak fire activities, Eq. (4) breaks down. In the evening, when the NL started to form, smoldering fires still constituted a source of particles at ground level and fresh smoke were trapped in the NL overnight. On average, the maximum particle concentrations were observed between sunset and midnight, and NL particle concentrations decreased slightly during the course of the night. This means that additional particle contribution from the smoldering fires later during the night to the shallow $(\sim 200 \mathrm{~m})$ and stable NL must - on average - have been rather small. 
As already noted, the aircraft observations indicate that the CBL was relatively well mixed until sunset, which means that the particle concentrations measured at ground level shortly before sunset should be similar to the those in the air entering the RL. Furthermore, sodar measurements (reaching up to $\sim 1500 \mathrm{~m}$ above ground) show a weakly turbulent RL due to wind shear, which further works to smear out any remaining vertical gradient during the course of the night. Despite this, the particle concentrations of the nocturnal RL estimated using Eq. (4) were significantly lower than those present when the RL was formed the preceding evening. This could also be seen directly from the strong decrease in concentrations during the turbulent hours. The same phenomenon was found when studying two flights made on adjacent days, in the evening 30 September 2002 and in the morning 1 October 2002. Coagulation of the RL aerosol is too slow a process to account for the particle losses, as is sedimentation into the NL. It appears that upward detrainment of aerosol from the uppermost CBL (or nocturnal RL) continued also after sunset, accompanied by downward entrainment of cleaner air from the CCL aloft, and that this process was strong enough to reduce the particle concentrations in the nocturnal RL considerably (Fig. 4). Since convection ceases after sunset, it is likely that other mechanisms are responsible for the vertical mixing, such as wind shear driven turbulence. The nocturnal RL is normally capped by an inversion that would otherwise prevent strong mixing of air parcels across the top of the RL. The uncertainties regarding the exact mechanisms and intensity of the mixing of the nocturnal RL with cleaner air masses aloft prevents a quantification of the extent of aerosol aging during one night by simply comparing the properties of the CBL shortly before sunset with what was being mixed down from the RL the next day. Neither is it possible to estimate the source strength of the biomass fires peaking in the afternoon using the available ground-level data.

Since the aerosol of the NL was seen to be stable and the overnight processing small, the processing of the aerosol in the nocturnal RL should also be minor, and any observed modification from the previous sunset should then largely be due to mixing with other air masses (detrainment of RL air and entrainment from the CCL aloft). Cloud processing is a strong candidate for all the observed modifications in aerosol properties; the decreasing number concentrations, the increase in particle size, and the increased number fraction of moderately hygroscopic particles. The cloud base is normally found at altitudes above the maximum CBL height, meaning that any cloud processed air has to enter the CBL and RL from above. Guyon et al. (2005) observed a shift towards larger sizes when comparing the number size distributions in fresh smoke plumes and air that had been detrained from pyrocumulus clouds into the cloud convective layer (CCL) overlying the daytime CBL. They attributed this size shift to cloud processing. Part of his cloud processed air can then be mixed down into the nocturnal RL.
The RL air being mixed down to ground level in the morning hours consisted of a mixture of an aerosol inserted into the RL the previous afternoon $(\sim 12 \mathrm{~h}$ old $)$ and a more aged aerosol that could have been processed during several days, possibly passing through several cloud cycles. The aerosol in the NL is dominated by freshly produced aerosol (less than $12 \mathrm{~h}$ old).

The freshly produced biomass burning aerosol was dominated by nearly hydrophobic particles. The fact that the number fraction of the nearly hydrophobic particles was lower in the RL (aged aerosol) than in the NL indicated that atmospheric processing gradually converted particles to the moderately hygroscopic group (Fig. 8). Plausible processes adding hygroscopic material are passage through clouds adding water-soluble gases to the droplets, condensation of water-soluble organic compounds and photochemistry producing low-volatility vapors that partition to the particles. Another process suggested by Gao et al. (2003) is the conversion of large organic species into simpler organic acids via ageing. This process could result in more hygroscopic compounds, which is contrary to the process suggested in Kalberer et al. (2004) of polymerization into larger organic compounds in the aerosol phase.

Detailed investigations of the chemical composition of the biomass burning aerosol at the FNS site were carried out both during the LBA-SMOCC experiment in 2002 (Decesari et al., 2005; Fuzzi et al., 2006 ${ }^{1}$; Falkovich et al., 2005; Schkolnik et al., 2005) and during the LBA-EUSTACH dry season experiment in 1999 (Graham et al., 2002; Mayol-Bracero et al., 2002). The dominant fraction of the aerosol mass in the fine particulate matter produced by biomass burning was found to be carbonaceous. The main inorganic species were sulphate, ammonium, and potassium. For the dry and transition periods, all the quantified inorganic compounds only add up to $8-11 \%$ of the total mass for particles with aerodynamic diameters $<0.42 \mu \mathrm{m}$, and only slightly more (14$19 \%$ ) for the wet period (Fuzzi et al., 2006 ${ }^{1}$ ). In the same size range, water-soluble organic compounds (WSOC) constituted $50-60 \%$ of the mass. This means that at least $60 \%$ of the mass of these particles consisted of water-soluble compounds that could contribute to their hygroscopic growth. This high mass fraction is not directly comparable with the soluble volume fraction calculated using ammonium sulfate as reference compound ( $\varepsilon_{A S}$, Eq. 1), which typically show much lower values (Table 3). But, as discussed in Sect. 2.2.4, the $\varepsilon_{A S}$ should not be interpreted as the real soluble volume fraction but merely as a description of the hygroscopic behavior measured by the H-TDMA data, representing the number of soluble molecules or ions within the particles as the volume fraction ammonium sulfate containing the same number of ions.

A more appropriate quantity for comparisons between the data from the HTDMA and the size-resolved chemistry is $\kappa$, representing the number of moles of soluble of ions or molecules per unit volume dry particles. Such a test of 
consistency between the data sets is essentially what is presented by Mircea et al. (2005). There, the hygroscopic diameter growth factors were calculated from the chemical composition, and compared with the H-TDMA measurements.

A detailed description of the composition of the organic aerosol during LBA-SMOCC is found in Decesari et al. (2005). Between $61-68 \%$ of the total carbon mass (TC) during dry and transition periods was water-soluble (WSOC). Only 9-11\% of the WSOC could be identified at the molecular level as poly-hydroxylated compounds, and aliphatic or aromatic acids. On the other hand, a functional group analysis was able to attribute as much as $50-90 \%$ of the WSOC into broad chemical classes (neutral species, light acids, and humic-like substances - HULIS). HULIS extracted from samples collected during the campaign showed low hygroscopic growth $\sim 1.05-1.1$ (Swietlicki et al., 2005). This is similar to the growth observations made in Gysel et al. (2004) of samples collected at a Hungarian site (Gf 1.08-1.17). HULIS are believed to form either directly from biomass burning (Mayol-Bracero et al., 2002) or via polymerization of lower-molecular organic compounds in the aerosol phase (Kalberer et al., 2004). Levoglucosan, formed by pyrolysis of cellulose, constituted $1-12 \%$ of the neutral species in the fine fraction, and is also slightly hygroscopic (Svenningsson et al., 2005).

During LBA-SMOCC and two previous campaigns at an Amazonian rain forest site, (Balbina) a group of particles with a hygroscopic growth factor around 1.25-1.3 (>110 nm) was found (Rissler et al., 2004; Zhou et al., 2002). Higher growth factors were rarely observed, even though the characteristics of the air masses studied were highly variable, including clean background air over the pristine rain forest, and aged (2-5 days) biomass burning aerosols. This implies that a growth factor $\sim 1.3$ (from dry to $\mathrm{RH}=90 \%$ ) appears to be a limit to the hygroscopic growth of the Amazonian sub-micrometer aerosol, irrespective of season. A likely explanation for this behavior is that the organic species dominate over the inorganic that are otherwise responsible for high hygroscopic growth factors. Even though a major fraction of the organic compounds are water-soluble, their comparatively high molecular weights and low degree of dissociation constrain their water uptake. While photochemical processing produces a variety of oxygenated compounds that might increase the hygroscopic growth, polymerization of low-molecular weight compounds into humic-like substances during aerosol aging further works to limit the attainable water uptake. Also the high precipitation rate has an influence on the observed $G f s$.

Only very few other H-TDMA studies of the hygroscopic properties of pyrogenic aerosol particle have been conducted. During very efficient combustion of biomass, for instance in biomass combustion units, nearly all organic material, including soot, are converted to $\mathrm{CO}_{2}$ or $\mathrm{CO}$, and the remaining potassium salts produce a highly hygroscopic aerosol (Rissler et al., 2005). However, in open-air biomass burn- ing, such optimum combustion conditions are rarely found. As noted by Guyon et al. (2005), the smoke sampled during SMOCC originated from a mixture of flaming and smoldering fires. Low growth factors similar to those observed during LBA-SMOCC were found in a laboratory study using controlled fires of various biomass fuels (Zeromskiene, 2004). The fuels used in that study were, however, not typical for the Amazon region. Dua and Hopke (1996) showed that the aerosol particles from flaming fires (burned in a non-optimized way) were hydrophobic (soot) while particles from the smoldering phase (non-combusted organic compounds) had a hygroscopic growth factor of around $\sim 2$, measured at $99 \%$ RH (corresponding to a $G f \sim 1.35$ at $90 \% \mathrm{RH}$ ). To summarize, in this study both freshly emitted and aged aerosol particles originating from biomass burning smoke had quite low hygroscopic growth factors.

\section{Conclusions}

The data presented here for the Amazonian biomass burning aerosol provides a detailed description of two of the most important aerosol particle physical properties - the dry submicrometer number size distribution and the hygroscopic properties. The measurements cover three meteorological periods: the dry period, the transition period, and the onset of the wet season.

During the three periods, the average number concentrations (average \pm 1 standard deviation) were $10440 \pm 6570$, $4810 \pm 2720$ and $1280 \pm 820 \mathrm{~cm}^{-3}(>30 \mathrm{~nm})$ in the dry, transition, and early wet season. The number size distributions always showed distinct Aitken $(\sim 70 \mathrm{~nm})$ and accumulation modes $(\sim 160 \mathrm{~nm})$, the latter being more variable in size from one period to the other (average modal GMD varying between $128-190 \mathrm{~nm}$ ). For the period with heavy pollution from biomass burning (dry period), the number size distributions were generally shifted to larger particle sizes than during the cleaner periods (transition and wet period). During the dry period, the CMD of the entire distribution, in the size range $>30 \mathrm{~nm}$, thus excluding the nucleation mode particles, was $135 \mathrm{~nm}$ while the corresponding CMD for the wet period was $90 \mathrm{~nm}$. A nucleation mode appeared occasionally (GMD $\sim 12 \mathrm{~nm}$ ), often being present during the evenings and until midnight as well as at sunrise. The appearance of nucleation mode particles were significantly different in character compared to the nucleation events observed at most other locations world-wide (Kulmala et al., 2004). The most likely explanation for this difference is that the SMOCC nucleation particles are related to micro- and not regional-scale meteorological phenomena.

The hygroscopic growth at $90 \% \mathrm{RH}$ revealed two groups of particles, here defined as the nearly hydrophobic group ( $G f \sim 1.09,110 \mathrm{~nm}$ particles) and moderately hygroscopic group ( $G f \sim 1.26,110 \mathrm{~nm}$ particles). The Aitken mode was always dominated by particles from the nearly hydrophobic 
group, while the fraction of moderately hygroscopic particles was significantly higher for the accumulation mode. The hygroscopic growth of these two groups was surprisingly stable from one meteorological period to another. The large difference in hygroscopicity comparing the three periods was seen in the fraction of particles belonging to each group. The nearly hydrophobic particles dominated during the dry period, while the fraction of moderately hygroscopic particles increased going into the wet period.

The peak fire activity took place during the afternoons. During this period, the group of particles having a growth $\sim 1.1$ dominated the particle distribution, i.e., particles emitted from biomass burning were predominantly nearly hydrophobic products of incomplete combustion.

At night, the shallow ( $\sim 200 \mathrm{~m}$ ) nocturnal stable layer (NL) at ground-level was decoupled from the overlying residual layer (RL). Fresh smoke from smoldering fires was trapped in the NL overnight. Throughout the campaign, a clear diel pattern was observed in particle concentrations, size distributions as well as hygroscopic properties. This is explained by down-mixing of more aged and processed aerosol from the residual layer (RL) aloft in the morning hours as the NL breaks up.

The particle properties of the aerosol in the RL were estimated based on the particle properties measured at ground level during the morning hours combined with the heights of the NL and the convective boundary layer, taken from the rawinsonde data. RL particle concentration was typically only $\sim 30 \%$ of that in the NL for the dry period, and $\sim 50 \%$ for the transition and wet periods. The median of the size distributions in the RL was shifted towards slightly larger sizes, by $11-32 \%$ compared to the NL averages. Only a very small increase in the hygroscopic growth of the nearly hydrophobic particles was seen in the RL compared to the NL, and none in the moderately hygroscopic particles. Instead, the fraction of particles belonging to the moderately hygroscopic group was larger in the RL than in the NL, with the largest difference seen during the transition and the wet period. This indicates that the aerosol particles grow in size and become more hygroscopic as a result of atmospheric processing. The particles that survive rainout and washout are shifted towards the moderately hygroscopic group of the accumulation mode. However, particles with a hygroscopic growth similar to that of common inorganic salts, such as ammonium sulfates and potassium chloride ( $G f \sim 1.7$ or higher), were not present. The likely explanation is that the oxygenated water-soluble organic substances that originate from biomass burning and that dominated the submicrometer aerosol mass have rather low hygroscopic growth factors. The same holds for the humic-like substances. Precipitation will also preferentially remove the larger and more hygroscopic particles.
Acknowledgements. This work was carried out within the framework of the Smoke, Aerosols, Clouds, Rainfall, and Climate (SMOCC) project, a European contribution to the Large-Scale Biosphere-Atmosphere Experiment in Amazonia (LBA). It was financially supported by the Environmental and Climate Program of the European Commission (contract No. EVK2-CT-2001-00110 SMOCC), the Max Planck Society (MPG), the Fundação de Amparo à Pesquisa do Estado de São Paulo, and the Conselho Nacional de Desenvolvimento Científico (Instituto do Milênio LBA). We thank all members of the LBA-SMOCC and LBA-RACCI Science Teams for their support during the field campaign, especially A. C. Ribeiro, M. A. L. Moura, and J. von Jouanne.

We also which to thank the Nordic centre of excellence, Research unit on Biosphere - Aerosol - Cloud - Climate Interactions, BACCI.

Edited by: S. Fuzzi

\section{References}

Andreae, M. O., Artaxo, P., Fischer, H., Freitas, S. R., et al.: Transport of biomass burning smoke to the upper troposphere by deep convection in the equatorial region, Geophys. Res. Lett., 28, 6, 951-954, 2001.

Andreae, M. O., Artaxo, P., Brandao, C., Carswell, F. E., Ciccioli, P., da Costa, A. L., Culf, A. D., Esteves, J. L., Gash, J. H. C., Grace, J., Kabat, P., Lelieveld, J., Malhi, Y., Manzi, A. O., Meixner, F. X., Nobre, A. D., Nobre, C., Ruivo, M. D. L. P., Silva-Dias, M. A., Stefani, P., Valentini, R., von Jouanne, J., and Waterloo, M. J.: Biogeochemical cycling of carbon, water, energy, trace gases, and aerosols in Amazonia: The LBAEUSTACH experiments, J. Geophys. Res., 107 (D20), 8066, doi:10.1029/2001JD000524, 2002

Andreae, M. O., Rosenfeld, D., Artaxo, P., Costa, A. A., Frank, G. P., Longo, K. M., and Silva-Dias, M. A. F.: Smoking rain clouds over the Amazon, Science, 303, 5662, 1337-1342, 2004a.

Andreae, M. O., Talaue-McManus, L., and Matson, P. A.: Anthropogenic modification of land, coastal and atmospheric systems as threats to the functioning of the Earth System, in Earth System Analysis for Sustainability, edited by: Schellnhuber, H.-J., Crutzen, P. J., Clark, W. C., Claussen, M. and Held, H., pp. 245264, The MIT Press, Cambridge, Mass., 2004b.

Artaxo, P., Fernandes, E. T., Martins, J. V., Yamasoe, M. A., Hobbs, P. V., Maenhaut, W., Longo, K. M., Castanho, A.: Large Scale Aerosol Source Apportionment in Amazonia, J. Geophys. Res., 103 (D24), 31 837-31 848, 10.1029/98JD02346, 1998.

Artaxo, P., Martins, J. V., Yamasoe, M. A., Procópio, A. S., Pauliquevis, T. M., Andreae, M. O., Guyon, P., Gatti, L. V., Leal, A. M. C.: Physical and chemical properties of aerosols in the wet and dry season in Rondônia, Amazonia, J. Geophys. Res., 107 (D20), 8081, doi:10.1029/2001JD000666, 2002.

Baron, P. A. and Willeke, K: Aerosol Measurement - Principles, Techniques and Applications, 2nd ed. New York , John Wiley \& Sons, 2001.

Chand, D., Guyon, P., Artaxo, P., Schmid, O., Frank, G. P., Rizzo, L. V., Mayol-Bracero, O. L., Gatti, L. V., and Andreae, M. O.: Optical and physical properties of aerosols in the boundary layer and free troposphere over the Amazon Basin during the biomass 
burning season, Atmos. Chem. Phys. Discuss., 5, 4373-4406, 2005 ,

SRef-ID: 1680-7375/acpd/2005-5-4373.

Crutzen, P. J. and Andreae, M. O.: Biomass Burning in the Tropics Impact on Atmospheric Chemistry and Biogeochemical Cycles, Science, 250, 4988, 1669-1678, 1990.

Davidson, E. A. and Artaxo, P.: Globally significant changes in biological processes of the Amazon Basin: Results of the Largescale Biosphere-Atmosphere Experiment, Global Change Biol., 10, 1-11, 2004.

Decesari, S., Fuzzi, S., Facchini, C., Mircea, M., Emblico, L., Cavalli, F., Maenhaut, W., Chi, X., Schkolnik, G., Falkovich, A. H., Rudich, Y., Claeys, M., Pashynska, V., Vas, G., Kourtchev, I., Vermeylen, R., Hoffer, A., Andreae, M. O., Tagliavini, E., Moretti, F., and Artaxo, P.: Characterization of the organic composition of aerosols from Rondônia, Brazil, during the LBASMOCC 2002 experiment and its representation through model compounds, Atmos. Chem. Phys. Discuss., 5, 5687-5749, 2005, SRef-ID: 1680-7375/acpd/2005-5-5687.

Silva Dias, M. A. F, Rutledge, S., Kabat, P., Silva Dias, P. L., Nobre, C., Fisch, G., Dolman, A. J., Zipser, E., Garstang, M., Manzi, A., Fuentes, J. D., Rocha, H., Marengo, J., Plana-Fattori, A., Sá, L., Alvalá, R., Andreae, M. O., Artaxo, P., Gielow, R., Gatti, L. V.: Clouds and rain processes in a biosphere atmosphere interaction context in the Amazon Region, J. Geophys. Res., 107 (D20), 8072, doi:10.1029/2001JD000335, 2002.

Dick, W. D., Saxena, P., and McMurry, P. H.: Estimation of water uptake by organic compounds in submicron aerosols measured during the Southeastern Aerosol and Visibility Study, J. Geophys. Res., 105 (D1), 1471-1480, 10.1029/1999JD901001, 2000.

Dua, S. K. and Hopke, P. K.: Hygroscopic growth of assorted indoor aerosols, Aerosol Sci. Technol., 24, 3, 151-160, 1996.

Falkovich, A. H., Graber, E. R., Schkolnik, G., Rudich, Y., Maenhaut, W., and Artaxo, P.: Low molecular weight organic acids in aerosol particles from Rondonia, Brazil, during the biomassburning, transition and wet periods, Atmos. Chem. Phys., 5, 781797, 2005,

SRef-ID: 1680-7324/acp/2005-5-781.

Ferreira da Costa, R., Feitosa, J. R. P., Fisch, G., Souza, S. S., and Nobre, C. A.: Variabilidade diária da precipitação em regiões de floresta e pastagem na Amazônia, Acta Amazônica, 28, 4, 395408, 1998.

Fisch, G., Tota, J., Machado, L. A. T., Dias, M. A. F. S., Lyra, R. F. D., Nobre, C. A., Dolman, A. J., and Gash, J. H. C.: The convective boundary layer over pasture and forest in Amazonia, Theor. Appl. Climatol., 78, 1-3, 47-59, 2004.

Graham, B., Mayol-Bracero, O. L., Guyon, P., Roberts, G. C., Decesari, S., Facchini, M. C., Artaxo, P., Maenhaut, W., Koll, P., and Andreae, M. O.: Water-soluble organic compounds in biomass burning aerosols over Amazonia - 1. Characterization by NMR and GC-MS, J. Geophys. Res., 107 (D20), 8047, doi:10.1029/2001JD000336, 2002.

Gao, S., Hegg, D. A., Hobbs, P. V., Kirchstetter, T. W., Magi, B. I., and Sadilek, M.: Water-soluble organic components in aerosols associated with savanna fires in southern Africa: Identification, evolution, and distribution, J. Geophys. Res., 108 (D13), 13 8491, doi:10.1029/2002JD002324, 2003.
Guyon, P., Frank, G., Welling, M., Chand, D., Artaxo, P., Rizzo, L., Nishioka, G., Kolle, O., Fritsch, H., Silva-Dias, M. A., Gatti, L. V., Cordova, A. M., and Andreae, M. O.: Airborne measurements of trace gas and aerosol particle emissions from biomass burning in Amazonia, Atmos. Chem. Phys., 5, 2989-3002, 2005,

SRef-ID: 1680-7324/acp/2005-5-2989.

Gysel, M., Weingartner, E., Nyeki, S., Paulsen, D., Baltensperger, U., Galambos, I., and Kiss, G.: Hygroscopic properties of water-soluble matter and humic-like organics in atmospheric fine aerosol, Atmos. Chem. Phys., 4, 35-50, 2004,

SRef-ID: 1680-7324/acp/2004-4-35.

Intergovernmental Panel on Climate Change (IPCC): Climate change, Third Assessment Report, Scientific Basis, 290-348, 2001.

Kalberer, M., Paulsen, D., Sax, M., Steinbacher, M., Dommen, J., Prevot, A. S. H., Fisseha, R., Weingartner, E., Frankevich, V., Zenobi, R., and Baltensperger, U.: Identification of polymers as major components of atmospheric organic aerosols, Science, 303, 5664, 1659-1662, 2004.

Kaufman, Y., Hobbs, P. V., Kirchhoff, V. W. J. H., Artaxo, P., Remer, L., Holben, B. N., King, M. D., Prins, E. M., Ward, D. E., Longo, K. M., Mattos, L. F., Nobre,C. A., Spinhirne, J., Thompson, A. M., Gleason, J. F., and Christopher, S. A.: Smoke Cloud and Radiation Experiment in Brazil (SCAR-B), J. Geophys. Res., 103 (D24), 31 783-31 808, doi:10.1029/98JD02281, 1998.

Kaufman, Y. J., Tanre, D., and Boucher, O.: A satellite view of aerosols in the climate system, Nature, 419, 6903, 215-223, 2002.

Kirkman, G. A., Gut, A., Ammann, C., Gatti, L. V., Cordova, A. M., Moura, M. A. L., Andreae, M. O., and Meixner, F. X.: Surface exchange of nitric oxide, nitrogen dioxide, and ozone at a cattle pasture in Rondonia, Brazil, J. Geophys. Res., 107 (D20), 8083 , doi:10.1029/2001JD000523, 2002.

Köhler, K.: The Nucleus in the Growth of hygroscopic droplets, Trans. Faraday. Sci., 32, 1152-1161, 1936.

Koren, I., Kaufman, Y. J., Remer, L. A., and Martins, J. V.: Measurement of the effect of Amazon smoke on inhibition of cloud formation, Science, 303, 5662, 1342-1345, 2004.

Kreidenweis, S. M., Köhler, K., DeMott, P. J., Prenni, A. J., Carrico, C., and Ervens, B.: Water activity and activation diameters from hygroscopicity data - Part I: Theory and application to inorganic salt, Atmos. Chem. Phys., 5, 1357-1370, 2005,

SRef-ID: 1680-7324/acp/2005-5-1357.

Kristensson, A., Johansson, C., Westerholm, R., Swietlicki, E., Gidhagen, L., Wideqvist, U., and Vesely, V.: Real-world traffic emission factors of gases and particles measured in a road tunnel in Stockholm, Sweden, Atmospheric Environment, 38, 5, 657-673, 2004.

Kulmala, M., Vehkamaki, H., Petajda, T., Dal Maso, M., Lauri, A., Kerminen, V. M., Birmili, W., and McMurry, P. H.: Formation and growth rates of ultrafine atmospheric particles: a review of observations, J. Aerosol Sci., 35, 2, 143-176, 2004.

Lohmann, U. and Feichter, J.: Global indirect aerosol effects: a review, Atmos. Chem. Phys., 5, 715-737, 2005,

SRef-ID: 1680-7324/acp/2005-5-715.

Massling, A., Stock, A., and Wiedensohler, A.: Diurnal, weekly, and seasonal variation of hygrscopic properties of submicrometer urban aerosol particles, Atmos. Environ., 39, 21, 3911-3922, 2005. 
Mayol-Bracero, O. L., Guyon, P., Graham, B., Roberts, G., Andreae, M. O., Decesari, S., Facchini, M. C., Fuzzi, S., and Artaxo, P.: Water-soluble organic compounds in biomass burning aerosols over Amazonia - 2. Apportionment of the chemical composition and importance of the polyacidic fraction, J. Geophys. Res., 107 (D20), 8091, doi:10.1029/2001JD000522, 2002.

Mircea, M., Facchini, C., Decesari, S., Cavalli, F., Emblico, L., Fuzzi, S., Vestin, A., Rissler, J., Swietlicki, E., Frank, G., Andreae, M. O., Maenhaut, W., Rudich, Y., and Artaxo, P.: Importance of the organic aerosol fraction for modeling aerosol hygroscopic growth and activation: a case study in the Amazon Basin, Atmos. Chem. Phys., 5, 3111-3126, 2005,

SRef-ID: 1680-7324/acp/2005-5-3111.

Patashnick, H. and Rupprecht, E. G.: Continuous PM-10 measurements using the Tapered Element Oscillating Microbalance, Journal of the Air \& Waste Management Association, 41, 8, 1079-1083, 1991.

Posfai, M., Simonics, R., Li, J., Hobbs, P. V., and Buseck, P. R.: Individual aerosol particles from biomass burning in southern Africa: 1. Compositions and size distributions of carbonaceous particles, J. Geophys. Res., 108 (D13), 8483, doi:10.1029/2002JD002291, 2003.

Prins, E. M., Feltz, J. M., Menzel, W. P., and Ward, D. E.: An overview of GOES-8 diurnal fire and smoke results for SCAR-B and 1995 fire season in South America, J. Geophys. Res., 103 (D24), 31 821-31 836, doi:10.1029/98JD01720, 1998.

Procópio, A. S., Artaxo, P., Kaufman, Y. J., Remer, L. A., Schafer, J. S., and Holben, B. N.: Multiyear analysis of amazonian biomass burning smoke radiative forcing of climate, Geophys. Res. Lett., 31, 3, L03108-L03112, doi:10.1029/2003GL018646, 2004.

Reid, J. S. and Hobbs, P. V.: Physical and optical properties of young smoke from individual biomass fires in Brazil, J. Geophys. Res.-Atmos., 103 (D24), 32 013-32 030, doi:10.1029/98JD02121, 1998.

Reid, J. S., Koppmann, R., Eck, T. F., and Eleuterio, D. P.: A review of biomass burning emissions part II: intensive physical properties of biomass burning particles, Atmos. Chem. Phys., 5, 799825,2005

\section{SRef-ID: 1680-7324/acp/2005-5-799.}

Rissler, J., Pagels, J., Swietlicki, E., Wierzbicka, W., Strand, M., Lillieblad, L., Sanati, M., and Bohgard, M.: Hygroscopic behavior of aerosol particles emitted from biomass fired grate boilers, Aerosol Sci. Technol., 39, 919-930, 2005.

Rissler, J., Swietlicki, E., Zhou, J., Roberts, G., Andreae, M. O., Gatti, L. V., and Artaxo, P.: Physical properties of the submicrometer aerosol over the Amazon rain forest during the wetto-dry season transition - comparison of modeled and measured CCN concentrations, Atmos. Chem. Phys., 4, 2119-2143, 2004, SRef-ID: 1680-7324/acp/2004-4-2119.

Schkolnik, G., Falkovich, A. H., Rudich, Y., Maenhaut, W., and Artaxo, P.: New analytical method for the determination of levoglucosan, polyhydroxy compounds, and 2-methylerythritol and its application to smoke and rainwater samples, Environ. Sci. Technol., 39, 8, 2744-2752, 2005.

Stolzenberg, M. R. and McMurry, P. H.: TDMAFIT user's manual, PTL Publications No. 653, Particle Technology Laboratory, Department of Mechanical Eng., University of Minnesota, Minneapolis, MN, USA, 1988.

Svenningsson, B.: Hygroscopic growth of atmospheric aerosol par- ticles and its relation to nucleation scavenging in clouds, ISBN 91-628-2764-2, Doctoral dissertation at Lund University, Dept. of Nuclear physics, Lund, Sweden, 1997.

Svenningsson, B., Hansson, H. C., Wiedensohler, A., Noone, K., Ogren, J., Hallberg, A., and Colvile, R.: Hygroscopic Growth of Aerosol-Particles and Its Influence on Nucleation Scavenging InCloud - Experimental Results from Kleiner-Feldberg, J. Atmos. Chem., 19, 1-2, 129-152, 1994.

Svenningsson, B., Rissler, J., Swietlicki, E., Mircea, M., Bilde, M., Facchini, C., Zhou, J., Monster, J., and Rosenorn, T.: Hygroscopic Growth and Critical Supersaturations for Mixed Aerosol Particles of Inorganic Compounds of Atmospheric Relevance, Atmos. Chem. Phys. Discuss., 2833-2877, 2005.

Swietlicki, E., Zhou, J. C., Berg, O. H., Martinsson, B. G., Frank, G., Cederfelt, S. I., Dusek, U., Berner, A., Birmili, W., Wiedensohler, A., Yuskiewicz, B., and Bower, K. N.: A closure study of sub-micrometer aerosol particle hygroscopic behaviour, Atmos. Res., 50, 3-4, 205-240, 1999.

Swietlicki, E., Zhou, J. C., Covert, D. S., Hameri, K., Busch, B., Vakeva, M., Dusek, U., Berg, O. H., Wiedensohler, A., Aalto, P., Makela, J., Martinsson, B. G., Papaspiropoulos, G., Mentes, B., Frank, G., and Stratmann, F.: Hygroscopic properties of aerosol particles in the northeastern Atlantic during ACE-2, Tellus Series B-Chemical and Physical Meteorology, 52, 2, 201-227, 2000.

Swietlicki, E., Rissler, J., Massling, A., Svenningsson, B., Bilde, M., Hoffer, A., Hoffer, G., Dusek, U., and Kiss, G.: Hygroscopic growth and critical supersaturations of Humic-like substances in atmospheric aerosols, EGU05-A-08932, Proc. EGU, 2005.

Tang, I. N. and Munkelwitz, H. R.: Water Activities, Densities, and Refractive-Indexes of Aqueous Sulfates and Sodium-Nitrate Droplets of Atmospheric Importance, J. Geophys. Res., 99 (D9), 18 801-18 808, doi:10.1029/94JD01345, 1994.

Trebs, I., Meixner, F. X., Slanina, J., Otjes, R., Jongejan, P., and Andreae, M. O.: Real-time measurements of ammonia, acidic trace gases and water-soluble inorganic aerosol species at a rural site in the Amazon Basin, Atmos. Chem. Phys, 4, 967-987, 2004, SRef-ID: 1680-7324/acp/2004-4-967.

Vestin, A.: Size distribution and cloud nucleating properties of biomass burning aerosol in the Amazon basin, Master's thesis, LUTFD2/(TFKF-5046)/1-63/(2003), Lund University, Dep. Of Nuclear Physics, Lund, Sweden, 2005.

Weingartner, E., Burtscher, H., and Baltensperger, U.: Hygroscopic properties of carbon and diesel soot particles, Atmos. Environ., 31, 15, 2311-2327, 1997.

Winklmayr, W., Reischl, G. P., Lindner, A. O., and Berner, A.: A New Electromobility Spectrometer for the Measurement of Aerosol Size Distributions in the Size Range from 1 to 1000 Nm, J. Aerosol Sci., 22, 3, 289-296, 1991.

Zeromskiene, K.: Physical characterization of laboratory-produced biomass burning aerosol particles, $\mathrm{PhD}$ thesis, Leibniz-Institute for Tropospheric Research, Leipzig, Germany, 2004.

Zhou, J.: Hygroscopic properties of atmospheric aerosol particles in various environments, $\mathrm{PhD}$ thesis, ISBN 91-7874-120-3, Lund University, Dept. of Nuclear Physics, Lund, Sweden, 2001.

Zhou, J. C., Swietlicki, E., Hansson, H. C., and Artaxo, P.: Submicrometer aerosol particle size distribution and hygroscopic growth measured in the Amazon rain forest during the wet season, Journal of Geophysical Research-Atmospheres, 107 (D20), 8055, doi:10.1029/2001JD000203, 2002. 